Article

\title{
Digitizing Vanishing Architectural Heritage; The Design and Development of Qatar Historic Buildings Information Modeling [Q-HBIM] Platform
}

\author{
Fodil Fadli *(D) and Mahmoud AlSaeed \\ Department of Architecture and Urban Planning, College of Engineering, Qatar University, Doha 2713, Qatar; \\ arc.m.alsaeed@gmail.com \\ * Correspondence: f.fadli@qu.edu.qa
}

Received: 1 February 2019; Accepted: 15 April 2019; Published: 29 April 2019

check for updates

\begin{abstract}
The documentation of vanishing architectural heritage includes intensive information and data gathering, filtering, classification and digitization. Enabling such an endeavor necessitates the act of documentation, which requires the cooperation of several professionals from different fields, extensive resources, precise organization, and robust structuring. Therefore, the design and development of an innovative digital platform to facilitate the interaction between users from different specialties is highly desirable to enable dynamic real-time preservation and protection of such invaluable heritage. The aim of this study is to investigate the existing Qatari built heritage, urban conservation methods and the principles of modern digitizing and archiving techniques to create a sustainable and interactive archiving platform-Qatar Historic Buildings Information Modeling (Q-HBIM) platform. This unique digital platform aims to respond to the needs of the society as well as the experts in the fields of urban heritage conservation and buildings restoration. A literature review was conducted on topics relating to Qatar urban heritage and the principles of three-dimensional digitization technology including an exploration of the aspects of sustainable urban preservation. Accordingly, site analysis (physical, photogrammetric and 3D scanning techniques were used), and in-depth interviews were adopted as the main data collection techniques. The findings of this study elucidate the principles of innovative architectural heritage digitization tools involving Building Information Modeling (BIM) technology and processes. It is anticipated that the present work will formulate an advanced and unique interactive archiving tool in the context of Qatar and GCC/MENA regions in the shape of the: Qatar Historic Building Information Modeling (Q-HBIM) platform.
\end{abstract}

Keywords: architectural heritage conservation; historic building restoration; digitization; BIM; Qatar Historic Building Information Modeling (Q-HBIM)

\section{Introduction}

Rapid urbanization and neglect of historic cores, sites and buildings has led to the fading of the indigenous vernacular architecture, culture, societal values and standards [1,2]. The protection of urban heritage serves as a necessity for preserving and enhancing its usefulness, while maintaining the essence and identity of a place. Preservation of historic buildings relates to a sustainable concept, where the monuments and historic sites constitute an important part of the past, present and future. The process of cultural (including built) heritage preservation is an unceasing practice that requires relevant data to be captured, analyzed, filtered, recorded, monitored and regularly updated. However, the data capture and management of the heritage structures can be effectively elaborated through digitized means. Thus, the action of the 'digitization of heritage' serves as a process of reinstatement and protection, integrating the physical 3D survey technique, building component, cataloguing and archiving [3], as well as the non-physical recording of rich semantics and data [2]. 
The recovery of historical buildings builds upon the workflow established in terms of data acquisition, registration/recording, processing and modeling. This process includes a series of operations such as surveying, drafting, post-construction monitoring and management [4].

The traditional methods of survey and measurement using manual tape and photographing are slow, time-consuming and generate a number of limitations. The data and measurement acquired through the survey are later transferred to engineering 2D drawings. These 2-dimensional drawings and graphics provide a very limited support document for the reconstruction of historic buildings. Additionally, the extension of 2D graphics to 3D models does not contain the complete information required [5].

Even though captured data undergo recording, filtering, classification and modeling; the updating and monitoring aspects related to heritage preservation have been neglected. Furthermore, an update of reconstruction work and the availability of data for decision-support making has been missed. Supportively, international preservation strategies direct focus towards digitizing historical cultural architecture [3]. Therefore, historic buildings preservation requires highly-advanced techniques of a semantic web-based representation, using an integrative mechanism based on digitization tools and processes.

The existing urban heritage data obtained through photographic, physical and socio-ethnographic surveys of historic buildings is not readily available for further rehabilitation and restoration planning initiatives. Thus, the research aims at bridging this gap through the design and development of a flexible and expandable digital interactive database, which would contain, classify and catalogue the Qatari historic buildings and sites, despite their current conditions (either in use, restored, closed, in ruins or disappeared). The research objectives can be listed as follow:

1. Evaluation of the historic buildings with respect to three basic data ontologies; the building itself with its surrounded site scale (investigating its morphology and use), the spaces (by analyzing previous and current uses) of the buildings and its components such as size, area, number of stories, construction materials, and so forth.

2. Designing a database model to structure, synthesize and digitize the data collected through both primary and secondary sources.

3. To analyze, evaluate and process the raw data to be visualized via the database/platform.

This is achieved through processes including collection, evaluation, analysis, visualization and continuous monitoring of data collected from the historic buildings.

The Qatar Historic Buildings Information Modeling (Q-HBIM) platform classifies, organizes, documents and manages the information related to existing and vanished Qatari (built) heritage. Q-HBIM provides the building preservation experts with a digital environment enabling the annotation of textual, numerical or graphical information related to vanished, vanishing or still existing built heritage. Furthermore, the flexibility of this digital database/platform allows further research to expand and enlarge the design framework gradually over time and space. Hence, this platform will pave ways for the laying out of a local Qatari charter for sustainable conservation strategies providing a greener and sustainable future adaptive re-use scenarios for the historic buildings and sites.

Moreover, this platform is considered as one of the very first intelligent and focused platforms in the region. Its success will lead to create several future opportunities for the other countries in the region to adapt the principles of smart digitization in the process of preserving and protecting built heritage. 


\section{Materials and Methods}

\subsection{Theoretical Background and Local Context}

\subsubsection{Cultural Heritage Preservation and Protection}

Different terminologies of heritage conservation, preservation and regeneration in the urban context refer to prevention of the decline of a city's environmental, socio-cultural and economic components of the related heritage. The documentation of remaining buildings and recording of ones that have disappeared would lead to the prevention of the decay of the physical structures in the location such as the building and monuments, while the definition expands to include the methods and guidelines of archiving and protecting the existing buildings [6]. Regeneration, preservation and conservation aim to integrate comprehensive processes and tools to resolve architectural and urban issues. Its main target is to create more sustainable, livable cities while preserving their historical and heritage context.

The action of heritage preservation encompasses various operations and interventions, and although these mainly involve physical actions, they simultaneously relate to social, cultural and economic needs. This is in order to enhance the physical and non-physical environment through the documentation and re-use of existing buildings as heritage components and improved infrastructures. It also aims to enhance residents' quality of life and protect city heritage as promoted in UNESCO convention (1972). This refers to the responsibility of the identification, protection, conservation and presentation to future generations of the cultural and natural heritage, which falls under the responsibility of city master-planning and governmental charters for heritage preservation [7].

In order to comprehend the importance of heritage protection the present research has identified the various types of intervention in cultural built heritage context. It is associated with its role and definition as per the following (Figure 1) [8]:

- Renewal: "Urban renewal is often presented as a natural process through which the urban environment, viewed as a living entity, undergoes transformation."

- Clearance: "Remove dereliction and insufficient conditions generally in slum areas throughout urban regeneration process."

- Redevelopment: "Deteriorated physical environments which have potential to receiving, removing existing buildings, gaining new projects and clearing re-used buildings."

- Rehabilitation: "Bring new functions into the buildings while the original character is preserved to remove unhealthy and deteriorated physical environments."

- Preservation: "Aims to not only prevent deterioration but also keep the urban fabric original."

- Conservation: "Add supportive materials into the existing urban fabric to ensure continuity of its durability and structural integrity."

- Restoration: "Returning a building, structure, site or objective to appearance of an earlier time by removing later material and by replacing missing elements and details."

- Revitalization: "Bring life into urban areas which have obsolescence due to changes and transformations of urban activity pattern."

- Reconstruction: "Reproduce original old urban structures which have been lost due to disasters, wars, fire and so forth, through archaeological, archival and literary evidence."

Even while being considered as seats of commerce, innovation, and culture; cities also represent traditions and a unique character evolving to a different heritage identity that formulates the principle of a good city design [9]. The importance of heritage has been expanding as a factor that can make or break the internationalization of cities, which in turn preserves and promotes city unique characteristics [10]. The argument expounded by Paddison and Miles clarifies that culture and city heritage should be used as an efficient tool with which to implement successful regeneration projects: "The role of culture 
has assumed unprecedented significance and that is redefinition as a source has enabled it to be used as the means for resolving political as well as socio-economic problems" [11].

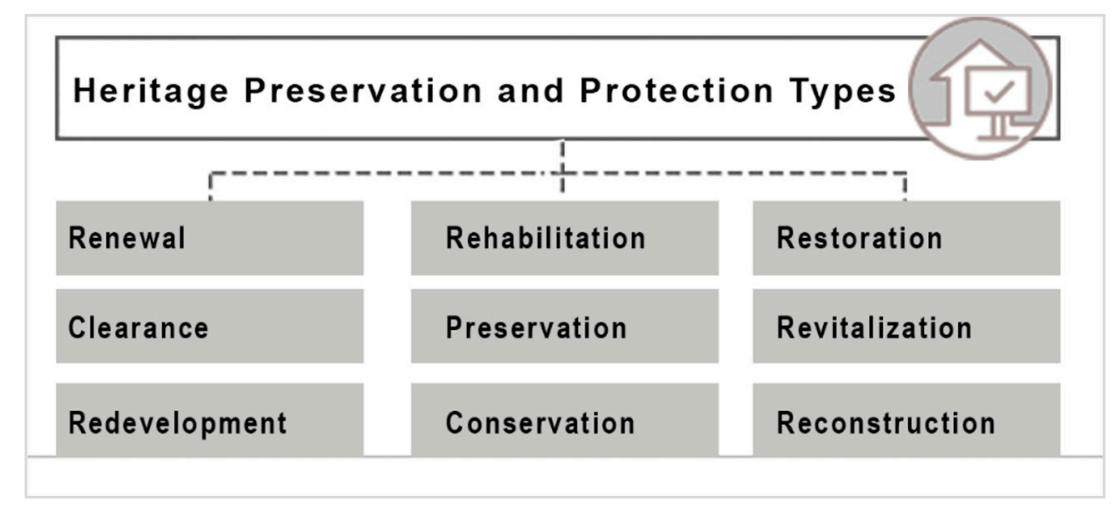

Figure 1. Heritage preservation and protection types (authors after Davoudi, S., S. Graham, and A. Madanipour).

The nineteenth century saw the first movement toward cultural preservation and regeneration as governments, artists, educational institutions, and social groups worked together to establish informal mergers of cultural strategies with the aim of revitalizing cities. The role of the culture industry can be defined as the revitalization of a city at the local and global levels alike. According to Lovatt and O'Connor (1995), "It is an important point that creativity and skills of people in the city should not be forgotten" [12]. Cultural regeneration and heritage preservation projects are important because they promote the city symbols that help enhance its national and international image [12]. These projects embody the meanings of rebirth, creativity, and modernism. They develop an interactive image of the city interactions with local and global economic and identity contexts. The importance of cultural and social activities depends on how they foster healthy competition between cities to formulate their representative images [10].

In order to do so, exploring and creating new methods of archiving and documenting cultural built heritage is a crucial and important task not only to protect the built forms but to preserve the city identity. In this respect, integrating technology as a powerful tool of monitoring and archiving plays a significant role to facilities such aims and reduce the cost and efforts of the preservation processes.

\subsubsection{The Digitization of Cultural Heritage}

Rapid development and the expansion of cities over historic sites and buildings have consumed the cities architecture, culture and heritage values and standards [13]. The need to capture the lost heritage is of high necessity with the unprecedented urban growth and cities expansion. The act of preservation is a sustainable concept where the city identity and cultural heritage constitute an important role in the past, present and future.

Undoubtedly, transferring the semantic of buildings and cities (the shape the heritage of nations) into an organized and detailed documentation is vital for heritage survival. However, the process of documentation requires an intensive cooperation between several fields that includes archaeology, history, architecture, civil engineering and information management. Each field focuses on a specific type of data sets and semantic information. The documentation itself requires large amount of resources, time and effort. In order to be listed and organized, this heterogeneous data sets are difficult to classify and hence are costly. Technology components of computer software, three- dimensional programs, scanning technology and information management systems could play a significant role in facilitating the documentation with an effective efficient approach. The process of digitizing the built heritage is developed upon the workflow of data acquisition, semantics, and 3D modeling. The process is complex and includes a series of operations that start with physical surveying, data analysis, drafting, modeling and monitoring the post- construction results [3]. 
The recent focus of scholars and scientists in the field towards developing a digitized method and related techniques comes as a response to growing challenges. The digital tools and techniques supersede conventional methods of data collection of measurement and survey using traditional techniques capture and measurements that are slow, time-consuming and lack accuracy and ability of customization. The previous method of drafting the buildings into two-dimensional drawings (2D) and graphics provided a very limited support document for the process of conserving and re-constructing the heritage buildings. Moreover, the modeling of 2D drawings into 3D models lack the information required $[14,15]$.

Although the data is collected, analyzed and categorized, updating and monitoring the detail of heritage preservation is usually dismissed, and moreover, the update of reconstruction work and the availability of data required for decision-making is overlooked. This extends the modern guidelines of heritage preservation and historic areas conservation which have started to adopt more advanced techniques of technology. This led to the representation through the integration of computer technology as procedures and tools [2].

\subsubsection{Digital Documentation Methods}

During the last two decades, digital documentation started to gain more attention amongst scholars and practitioners in the field. Not only because of its wide range of applications and ability for customization, but also due to its flexible implementation at different levels of the archival/documentation process. Digital archiving in heritage preservation plays a significant role to preserve records and reconstruct buildings data. This includes 3D models and related semantics. Digitization of lost heritage allows scholars, scientists and authorities to monitor, filter and classify mega data into readable structures. In order to comprehend documentation processes typologies, this research has identified three categories of documentation methods according to the scale of the project as per the following:

A) Digitized recording/archiving of objects: This refers to various processes used in recording, archiving and creating three-dimensional models for specific objects. The later ones refer to cultural value such as sculptures, tools, and gadgets, where the scale of these objects is commonly small and easy to handle. The process of objects digitization encompasses several techniques and methods:

- Laser scanning method: This method depends on the principle of triangulation to extract the geometry of the objects. This method has high capacity to capture the details of the objects surface creating geometrical maps. However, the method is not able to create textures or distinguish material differences. This is considered as a disadvantage in case of multi-material objects [16].

- Structured light beams method: This method uses techniques of light projection in a specific pattern that focus on the surfaces of the object to generate the deformation information from the reflected patterns of light. This method is cost-effective when compared to laser scanning. However, it is less accurate and lacks higher resolution imaging [17].

- Silhouette formation method: Villeme founded this method in late 1960s. It was also known as the photographs-sculpturing method. The concept of this method is simple and based on taking multi-photographic images of the studied object from different angles. This would enable the creation of continuous and detailed visual mapping of the object under-study (Figure 2). These maps are then analysed and observation locked as side notes [18].

- Shadow structuring method: This method has been formulated as an application of the structured light beams. It creates a deformation map of the object surfaces through the concentration of shadow. This is a low-cost method using simple instruments. Despite having lower accuracy compared to the other tools, it has been applied to record and archive objects of large (urban) scale applications [19]. 


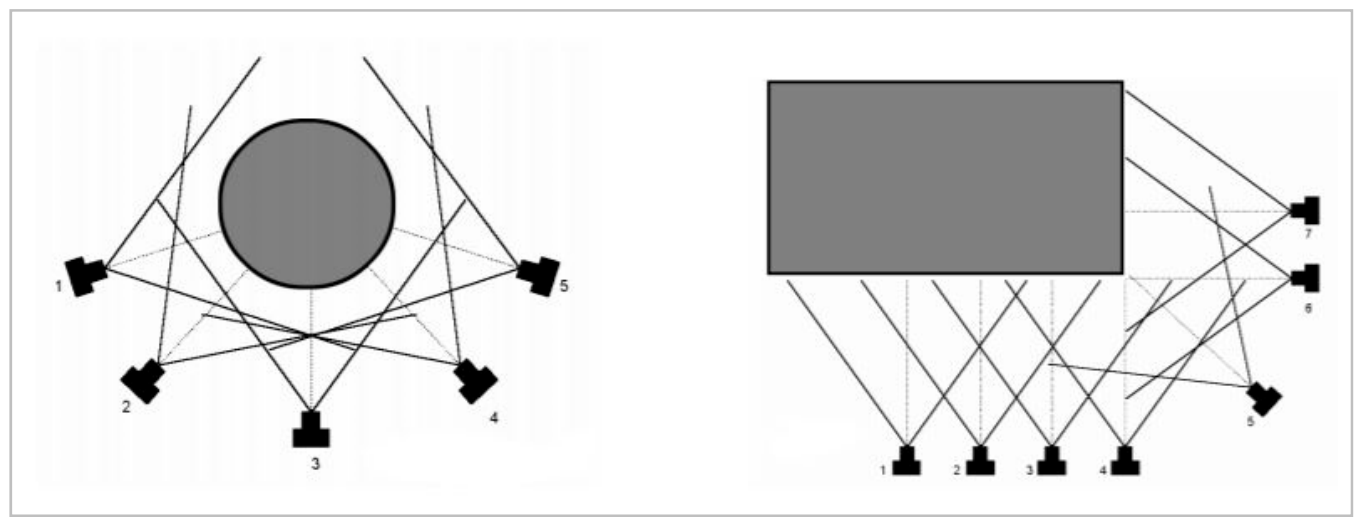

Figure 2. Silhouette formation method (source: Hanke \& Grussenmeyer. Corfu, 2002).

A multitude of digital archiving and recording techniques exist, such as the texture, focus, video recording, and photogrammetry methods. Although these methods are efficient and capture a considerable amount of details, they still deal with small-scale objects only. Table 1 develops an analytical comparison between these digital archiving-recording methods and techniques.

Table 1. A comparative analysis of digitized archiving-recording methods (objects scale).

\begin{tabular}{|c|c|c|c|c|c|c|c|}
\hline \multirow[b]{2}{*}{ 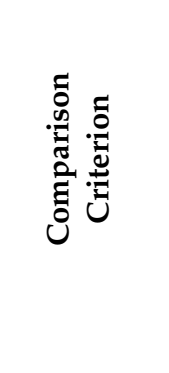 } & \multirow[b]{2}{*}{ 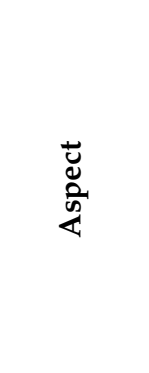 } & \multicolumn{6}{|c|}{ Method } \\
\hline & & 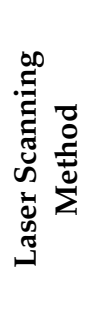 & 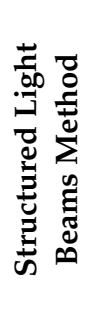 & 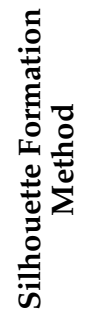 & 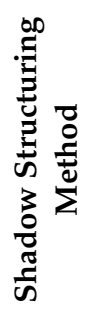 & 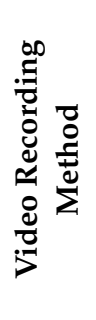 & 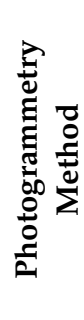 \\
\hline \multirow{2}{*}{ Cost } & Low & & 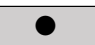 & & 0 & & 0 \\
\hline & High & $\bullet$ & & $\bullet$ & & $\bullet$ & \\
\hline \multirow{2}{*}{ Mobility } & Easy & & & 0 & 0 & 0 & 0 \\
\hline & Difficult & $\bullet$ & - & & & & \\
\hline \multirow{2}{*}{ Complexity } & Simple & & 0 & 0 & - & - & - \\
\hline & Complex & - & & & & & \\
\hline \multirow{2}{*}{ Accuracy } & Low & & & - & - & & \\
\hline & High & ○ & $\bullet$ & & & $\bullet$ & $\bullet$ \\
\hline
\end{tabular}

B) Digitized recording archiving of monuments (building) scale: The digitization of monuments is challenging and difficult because of their location in non-controlled environment as they are part of city components. Formulated from the techniques of object-digitization, this study has identified several techniques of monuments digitization as per the following:

- Empirical recording: This method is considered as one of the oldest methods used to create a visual record (by measures and sketches) for the studied-monument. It uses manual techniques of measurement to create a coordinates list of the building's surfaces. Although, considered as a low-cost efficient technique, it lacks accuracy and is limited to simple shaped buildings only [20].

- Topographic recording: This method adopts the principles of a 3D coordinate system. It uses advanced measurement techniques and devices such as Geodesic Station. This enables the creation of a complex points-map for the monument/building under study. Each point reflects accurately related coordinates, which are then graphically represented into meaningful models and drawings. It is hence considered to be a reliable and accurate technique that enables fast generation of 3D 
models. Its major limitation is the need for long set-back distances as well as the large size of equipment used [21,22].

- 3D Scanning: This is one of the most advanced applications of geodesic stations with high accuracy data capture. The method combines techniques including laser scanning, 3D surveying coordinates system and 3D modelling processing. It uses high performance and high accuracy 3D scanners, which offer great mobility and ease of movement. It enables the generation of 3D models in accordance with the aims of the investigation. The processing time may be long depending on the size of point cloud data sets [21,23].

- Structure from motion (SfM): The visual data capture of an object encompasses a great amount of 2D information. In this respect, the Sfm method provides the basis of transferring 2D data into 3D models. The Sfm method works on capturing a great number of photographs in specific angles associated with unique Global Positioning System (GPS) coordinates. It is most suitable for horizontal mapping and geo-localization rather than vertical data capture [23,24].

- Photogrammetry method: It is a simple and accurate method for recording building structures. It has good visual representation abilities and adopts the use of geometry principles combined with photography techniques, in order to develop 2D and 3D data sets of the studied structure. It is flexible in use for both simple and complex objects with high surface detail. It has efficient results that translate to observation sketches, 2D CAD representations as well as basic 3D models (Figure 3) [23,24].

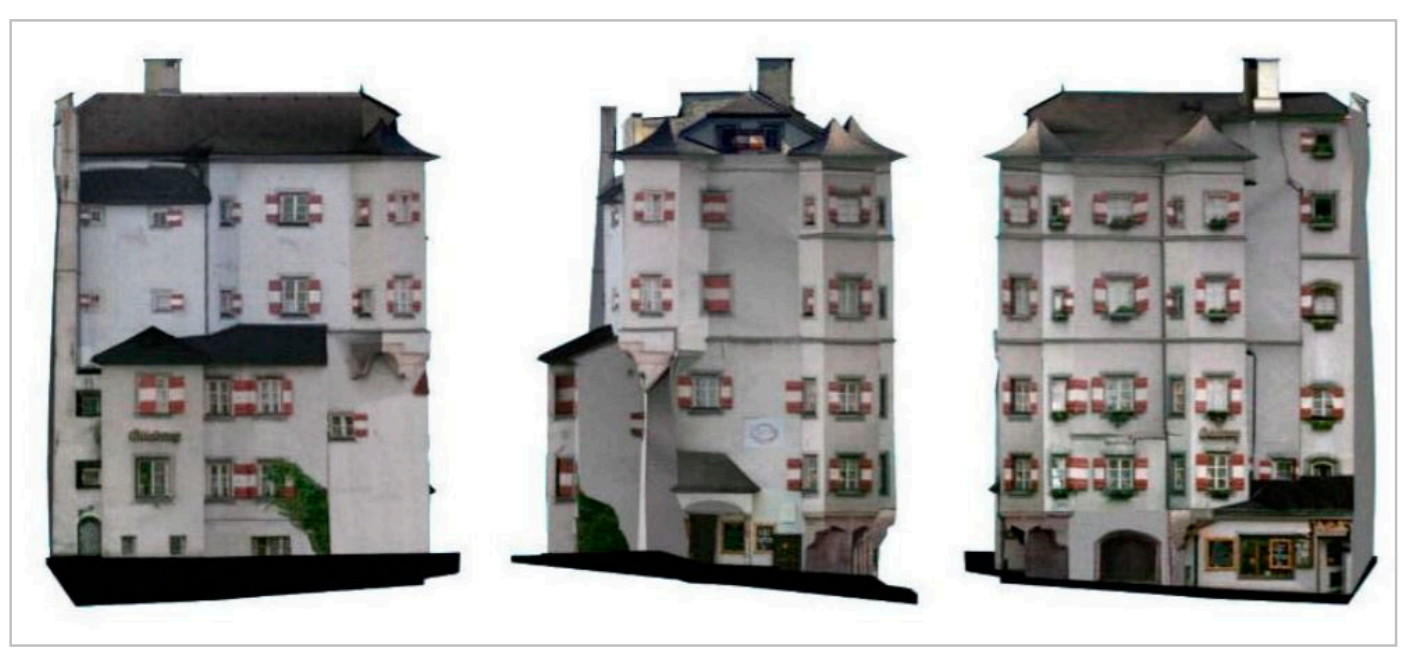

Figure 3. Photogrammetry-3D model of historical building (source: Hanke \& Grussenmeyer Corfu, 2002).

Table 2 compares major methods used in the digital recording and archiving of built heritage. The comparative analysis is built upon cost, mobility, accuracy and complexity criteria. It is notable that while the SfM and Photogrammetry methods present good accuracy and time-efficiency aspects in term of cost-productivity factors, the 3D Laser Scanning method presents the most accurate technique despite its cost and lengthy data processing post-data capture. 
Table 2. Comparative analysis of digital heritage recording methods (building scale).

\begin{tabular}{|c|c|c|c|c|c|c|}
\hline \multirow[b]{2}{*}{ 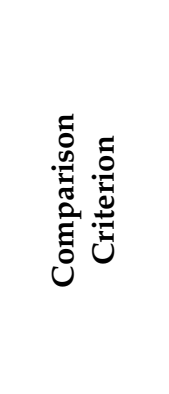 } & \multirow[b]{2}{*}{$\begin{array}{l}\overrightarrow{\tilde{u}} \\
\text { के } \\
\frac{\alpha}{4}\end{array}$} & \multicolumn{5}{|c|}{ Method } \\
\hline & & 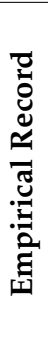 & 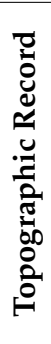 & 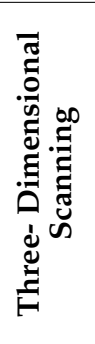 & 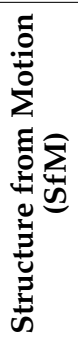 & 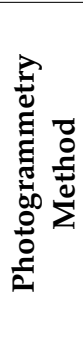 \\
\hline \multirow{2}{*}{ Cost } & Low & 0 & & & 0 & - \\
\hline & High & & $\bullet$ & $\bullet$ & & \\
\hline \multirow{2}{*}{ Mobility } & Easy & - & $\bullet$ & & $\bullet$ & $\bullet$ \\
\hline & Difficult & & & $\bullet$ & & \\
\hline \multirow{2}{*}{ Complexity } & Simple & - & $\bullet$ & & - & - \\
\hline & Complex & & & $\bullet$ & & \\
\hline \multirow{2}{*}{ Accuracy } & Low & - & & & & \\
\hline & High & & $\bullet$ & • & $\bullet$ & $\bullet$ \\
\hline
\end{tabular}

C) Digitized recording of sites (site scale): Entire sites (group of buildings, monuments and objects) are considered to be important to the heritage with significant cultural values and aspects that need to be recorded and protected. This section presents and discusses major methods used for this purpose. They are as follow:

- The Photogrammetry method: This is considered to be the easiest and fastest method used to capture the information for documentation. The photography technique provides a good level of information that shows the buildings characteristics. At the same time, the photos of the object are easy to be understood, analysed and interpreted by different users; academics, professionals, and students. Nevertheless, the nature of photographs that show different level of shades makes it difficult to analyse all information causing inaccuracy in the analysis result. Figure 3 above, demonstrates the loss of detail due to the shades and shadows of related photos involving focus point and geo-location.

- Empirical terrestrial surveys: This method is referred to as the 'manual survey' of a site. The surveyor uses conventional tools such as measuring tape, laser distance measuring instrument, and a spirit level to conduct the on-site-measured surveys and drawings. Data capture, in this case, focuses only on major aspects rather than specific details. Smaller details would be missed since a sketch must be finalized before the survey permanently records the captured data. Thus, this technique is highly recommended for fast facades and layout recording (Figure 4) [25]. Recurrent visits to the site are necessary, as data is lost while recording 2D graphic representations.

- LiDAR data collection technique: This is an advanced 3D scanning method that was introduced in the 1970s by the National Aeronautics and Space Administration (NASA). Nowadays, it represents the most available advanced used technology to conduct data capture, measurement and document sites and buildings. LiDAR technology uses laser-scanning tools that capture object dimensions, shapes, and configuration which are translated into 3D models. LiDAR technology is widely used by experts in the fields of archaeological, architectural, and environmental surveying (Figure 5) [25,26]. 


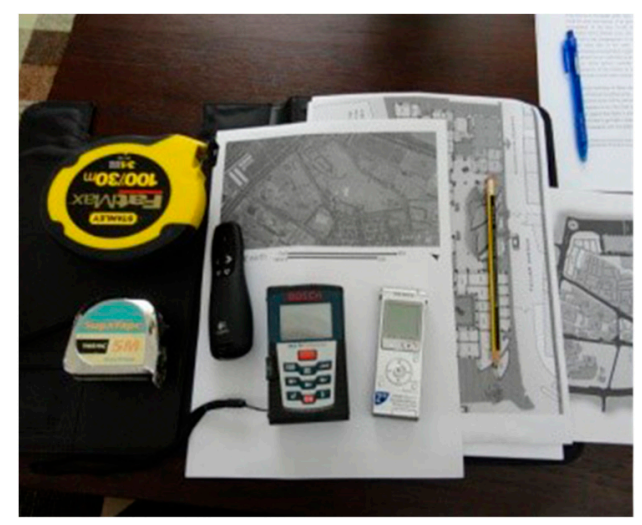

Figure 4. Conventional tools used in terrestrial (manual) survey (authors, 2012).
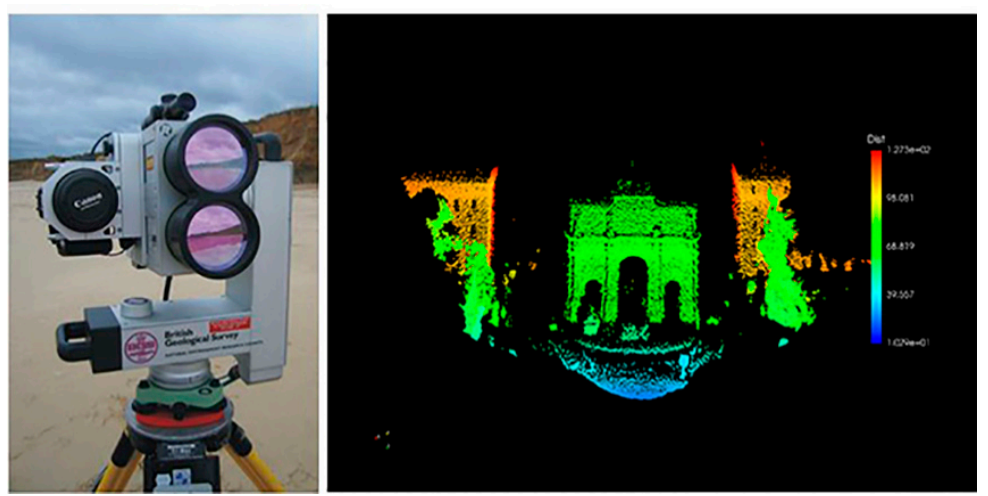

Figure 5. LiDAR scanning equipment and scanning result (Courtesy of Blickfeld, 2018).

Table 3 develops a comparative analysis of the methods used in the digitized sites recording and related data capture.

Table 3. A comparative analysis of digitized sites recording methods (site scale).

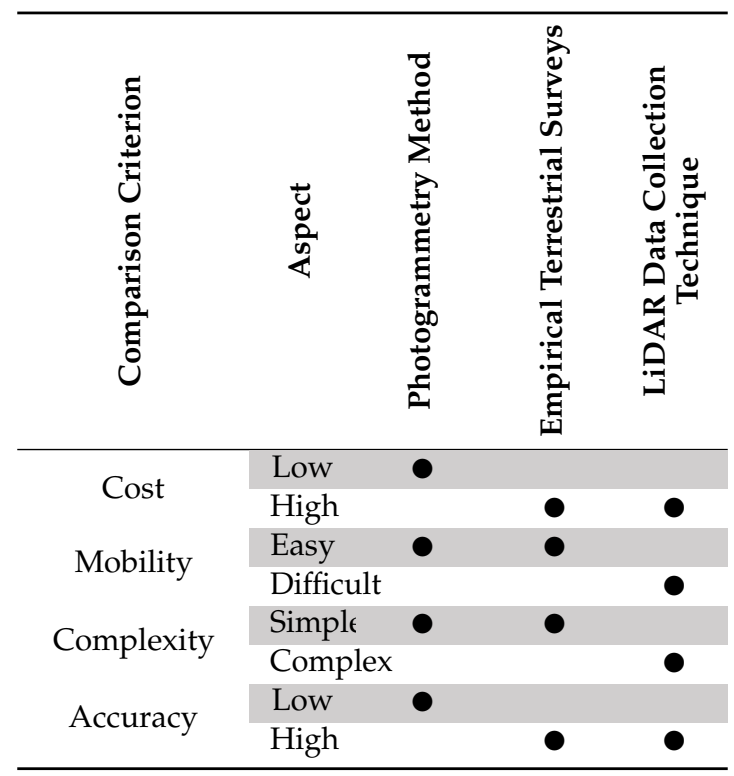

Although there has been a rapid development of accurate high-tech digital recording techniques and methods, the availability of such tools is limited to experts and highly costly. In such cases, database updates of related projects use a considerable amount of time, and human and financial resources. 
There is an urgent need to develop a semi- to full-real time-shared platform/environment that is open for all users and stakeholders. This will facilitate data acquisition, processing and filtering, while the fast and easy upgrade is highly desirable and required in preserving built cultural heritage [27].

\subsubsection{The Application of Digital Archiving}

Digitizing heritage recording and archiving is a vast field of research and includes several aspects and dimensions. In this research, focus is stressed upon two main points; 1 . The application of the digital recording and archiving on disappeared, existing, or converted structures, and 2. Integrative monitoring of the cultural heritage and decision-support system enabled through the digital platform.

\section{Digital Recording Archiving and Monitoring of Cultural Heritage}

The web-based and virtual archiving provides long-term saving and self-sufficient systems. Different dataset types are required for continuous monitoring, especially in the case of built heritage. Cultural built heritage suffers from continuous damages and hazards of natural and man-made origins. In this case, where these damages and changes are discovered at an advanced stage of decay, a need of continuous monitoring and immediate remedy is crucial. Regular and accurate 3D scanning using up-to-date techniques and tools for data capture and processing is required to detect and record all information which could be used for the reconstruction of damaged or disappeared heritage [3].

Information Management as Decision Making Support

Multimedia information management systems such as the three-dimensional navigation and animation provides two advantages: $i$. The first is the ability to show the order of scenarios and sequences of heritage development, ii. The second includes the capacity to display and represent the information and data in 3D navigation environment. This strengthens the delivery of a powerful insight of information that cannot be comprehended from a conventional analogue platform of archiving, recording and processing. Furthermore, it also offers the ability to combine several types of information together such as historical documents, physical conditions narratives and contemporary observation. This produces the development of an enabling decision-making tool in order to preserve and protect built cultural heritage over long spans of time [28].

\subsection{Area of Study}

The fieldwork took place over a series of on-site visits and data acquisition campaigns over a five year period. Surveys including photogrammetric, 3D scans and socio-cultural observations and interviews were conducted to cover the State of Qatar historic sites in Doha, Al Wakra, Al Khor, Zubara, Jumeilah, Umm-Sallal-Mohamed and Dukhan.

\subsection{Participants of the Study}

Participants involved in the research included owners of historic buildings (either existing or dilapidated structures), architects, designers, sociologists, restoration experts and institutions dealing with the safeguarding of heritage and traditional buildings in Qatar such as Qatar Museum Authority (QMA)-Dept. of Architecture, Ministry of Culture, Arts and Heritage, Ministry of Municipality \& Environment, and other related municipalities (al-Baladiyate). Governmental institutions as well as private sources provided divers maps, drawings, photos, and other relevant documents.

\subsection{Methodology}

In accordance with the recording and conservation process, historic buildings were assessed within three basic data groups inclusive of: buildings with the surrounding site scale, spaces of the buildings, and building components. Digitizing built cultural heritage involves two major components: building conservation decision-making and web-based visual representation using information systems. 
The documentation/recording of data constitutes an important aspect, further enabling evaluation, visualization and continuous data monitoring. The research methodology develops through four stages as represented in Figure 6 below.

1. Documentation of data-This phase covers the initial data collection through primary and secondary sources, forming the input of the Q-HBIM. This includes the physical and photographic surveys of the buildings and the socio-ethnographic data collection, together with the assembly of (secondary) data from different sources.

2. Database model design and synthesis-This phase includes designing the database, organizing and structuring the collected data for digitizing, based on a series of topics related to social, cultural and ethnographic importance.

3. Data processing and evaluation-This phase responds to the queries made between different data topics, converting the raw data into processed form and classifying the data for further analysis.

4. Data catalogue-The final phase provides a visual experience of the input data using digital technologies. This expands the horizons for cultural heritage interactivity, data management and monitoring.

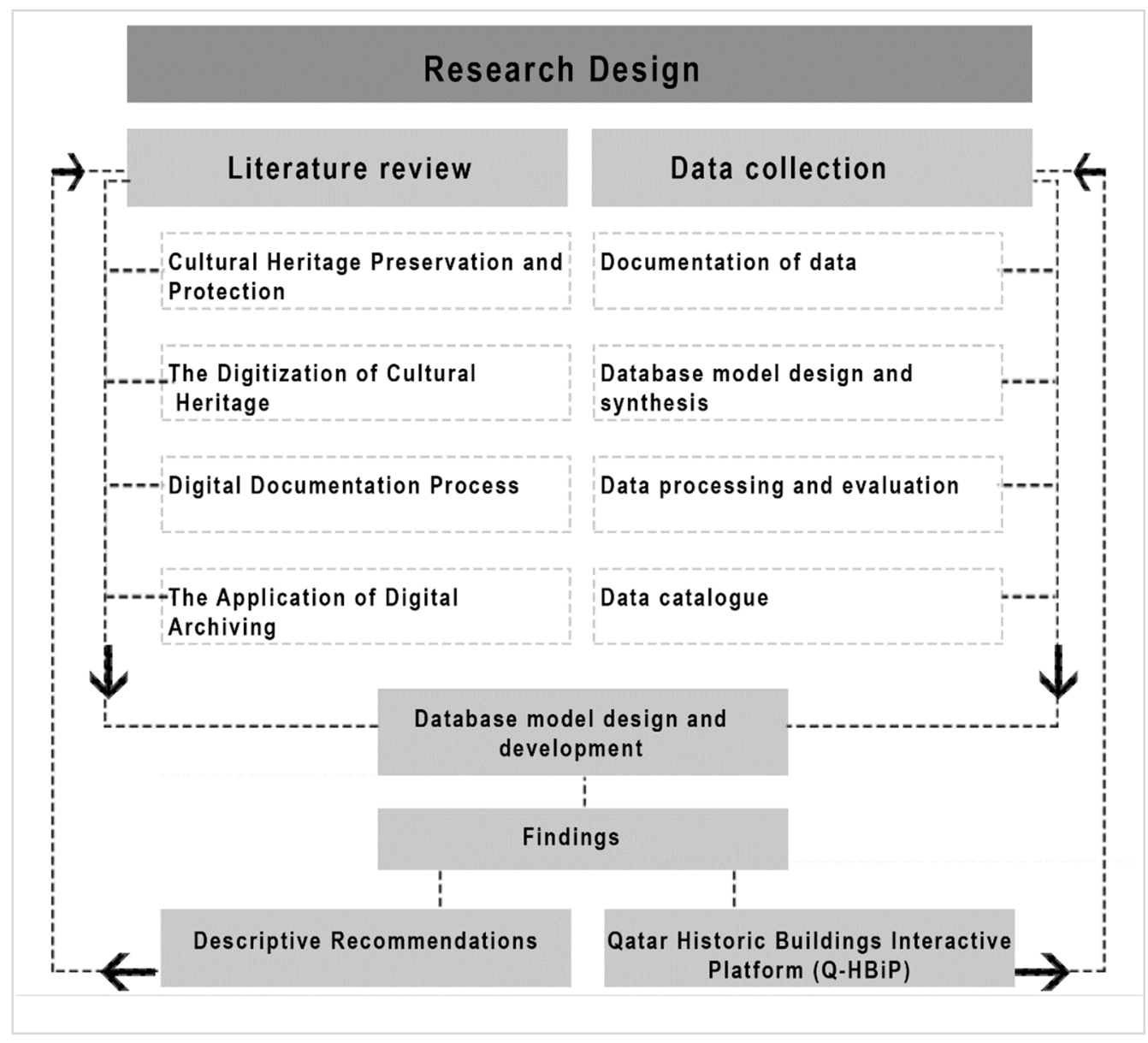

Figure 6. Research method: design and stages.

\subsubsection{Data Identification}

The data collected and used in this research are primary as well as secondary data. However, qualitative analysis is needed to codify and standardize parts of the primary and secondary data. This relates to the part integration of in-depth interviews and evaluating existing photographic and physical 
surveys as well as archival documents when available. Almost all the data used in the quantitative analysis are secondary data, collected from previous work on studied buildings

- Primary data was collected during fieldworks and on-site visits, but also through questionnaires and interviews with occupants, owners and restoration/conservation experts in Doha. The empirical investigation is based on fieldwork where important and rich data was collected.

- Secondary data was collected from archival (written pieces and drawings) documents. Secondary data was used to evidence the photographic and physical surveys when the buildings were deteriorated partially or fully damaged or vanished.

\subsubsection{Research Instruments}

A set of techniques and tools were used in this research to identify, gather, analyze and synthesize the data of historic buildings in Qatar. These include the following:

On-site Physical and Photographic Surveys

This research builds upon several site visits to different historic sites in Doha, al Wakra, al Khor, Zubara, Jumeilah, Umm Sallal Mohamed, and Dukhan. Several visits took place between 2011 and 2015, during comfortable outdoor working climatic conditions. During these visits, data was acquired from the sites through: photos, diagram, sketches and physical measurements. Sets of collected data were analyzed and categorized using excel sheets then exported and translated via FileMaker Pro (vrs.7, then 12 , and 17) software to enable coding and description of each study subject by its: (1) name, (2) type of ownership, (3) physical condition, (4) geo-context identification and, (5) historical background.

Interviews and Questionnaires

Interviews were conducted with architects/restoration experts and also with institutions dealing with the safeguarding of heritage and traditional buildings in Qatar, such as Qatar Museum Authority (QMA)-architecture Department, Ministry of Culture, Arts and Heritage, Ministry of Municipality \& Urban Planning, and al Baladiyate (municipalities).

Previous Studies and Survey

Studies and research based on surveys of the historic and old buildings and urban areas in Qatar remain rare and scarce. The latter ones are mainly archeologically and ethnographically oriented. Overall about eight research teams worked on topics related to studying the old and historical buildings and areas in Qatar, of which only two conducted thorough surveys of the remaining and vanishing historic buildings.

- The surveys of old historical Qatari buildings conducted by GHD (an Australian management, engineering and environmental company) in association with the Building Engineering Department for the Supreme Council of Culture was the most detailed and prominent surveying study. The study, conducted between 2000 and 2004, culminated in some detailed reports and architectural drawings for the few remaining and almost vanished historic structures in Qatar.

Al Jaidah and Bourennane developed their work which resulted in the book "The History of Qatari Architecture-1800-1950" based on GHD-BED surveys and report (Jaidah and Bourennane, 2009). Boussaa conducted similar research but on restricted number of buildings in his work conducted between 2008 and 2011 on the conservation of heritage in Qatar. Earlier work was conducted by the Danish archeological mission (1950s) but was mainly targeting historical archeological sites. The French archeological mission was one of the precursors in the field despite its focus on generic topics mainly related to ethnography and archeology (Tixier, The French Archeological mission in Qatar, 1984/85). Mohamed Al-Khulaifi was a Qatari researcher who conducted a comprehensive work on Qatari popular traditional architecture, which was completed by the publication of two manuscripts 
on folk buildings in Qatar, and the architecture of the old palace. The latter work was conducted under the patronage of the National Council for Culture, Arts and Heritage, the Museum \& Antiquities Dept (QMA). The major studies and surveys are rare and since the 1980s, there was not much interest in studying and recording traditional and cultural heritage Qatari architecture. Since the start of the new millennium, there is, however, a clear interest and enthusiasm in studying this vanishing architecture. However, there are only a few studies and research projects aimed at recording and surveying historic buildings, structures and areas in the major historic cities and towns of Qatar

\section{Data Analysis Interpretation}

From the data collected and analyzed from the study locations, houses and residential buildings have been preserved to a certain extent, however they have faced either partial demolition, modification or total reconstruction. Their use has been retained or new purposes were assigned. Forts, fortresses and towers represent the military buildings. These categories represent the oldest historic buildings in Qatar. To this extent, this section is dedicated to combining the data collected with computer intelligent solution to formulate Qatar Historic Buildings Information Modeling (Q-HBIM) platform, aiming to create the most suitable and effective method of cultural heritage preservation and protection.

\subsection{Database Model Design and Development}

In order to design a flexible method of information categorization and analysis, the current study developed a tool that uses the principle of BIM. This includes information modeling main process of collecting and transferring captured data from a descriptive status to a 3D model fed by related semantics. The process evolves over three stages (Figure 7):

01. Empirical survey: A manual survey of the studied buildings categorizes the heritage buildings according to related aspects such as current condition, location, year of construction, area of the building, construction materials, and building height. Other criteria consider the use and ownership classification, which include the current, previous and future planned use, as well as ownership type.

02. Data semantics and organization: Two-dimensional and 3D models of the building are produced post-data capture. This process uses conventional CAD systems converting data from points and figures to drawings and graphical representations

03. Data extraction: The generated 3D models contain a large amount of data information, which is meant to process, synthesize and filter. Post-processed data is then extracted and linked to the 3D models of the building as a related semantic-data.

The expandable flexible database has been designed as an original interface, using the FileMaker Pro vrs. 7 and updated to vrs.12/17 software packages. It is a matrix-based model database, which would work as an extendable container-storage-filter-recorder and classifier. The schematic diagram below (Figure 8) shows the database design, structure, and "organigram", together with the iterative continuous process of surveying (photographic, physical and socio-ethnographic) and the multitude of ways of approach and the flexibility of the database model. 


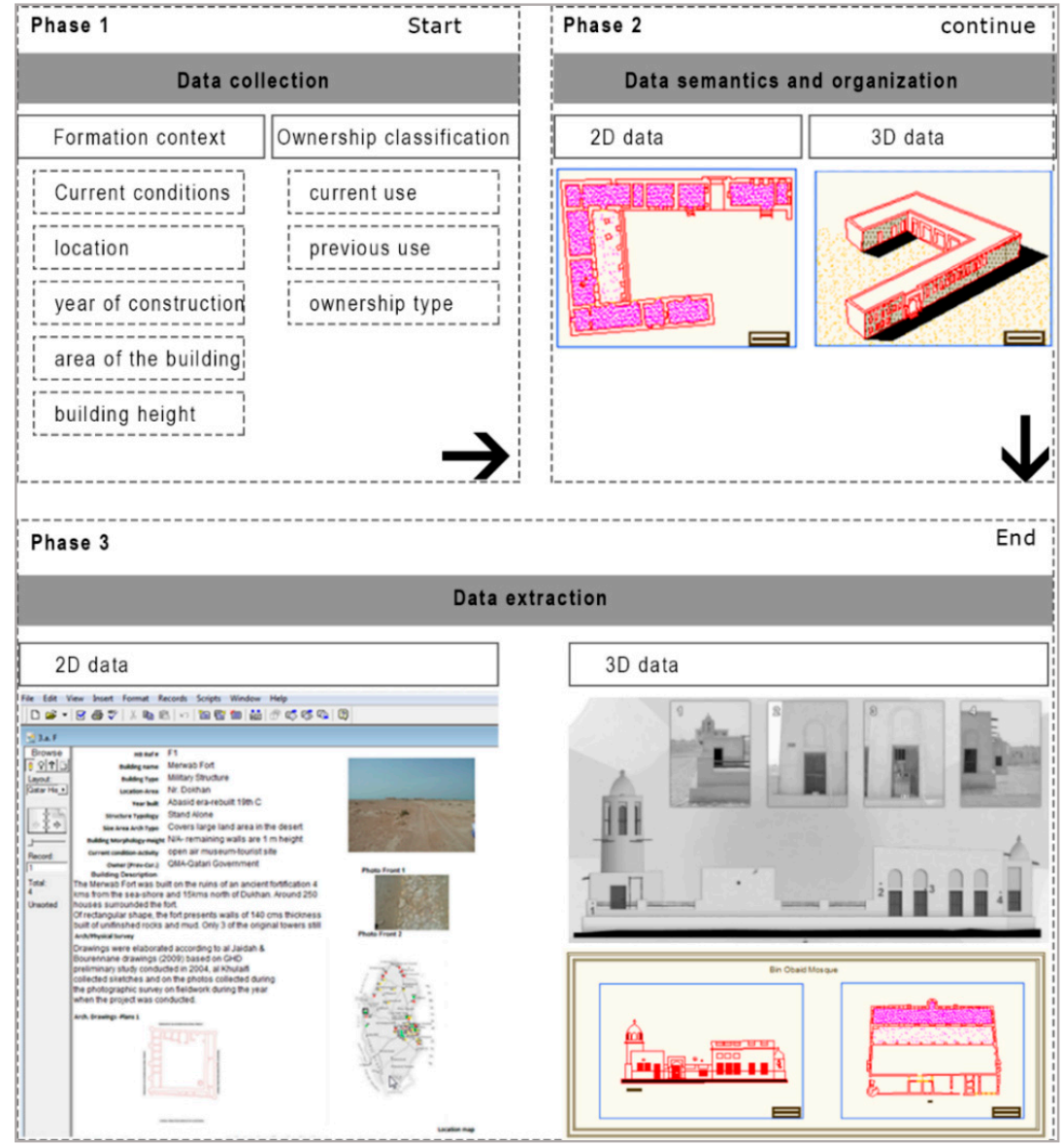

Figure 7. Data collection and processing towards BIM model.

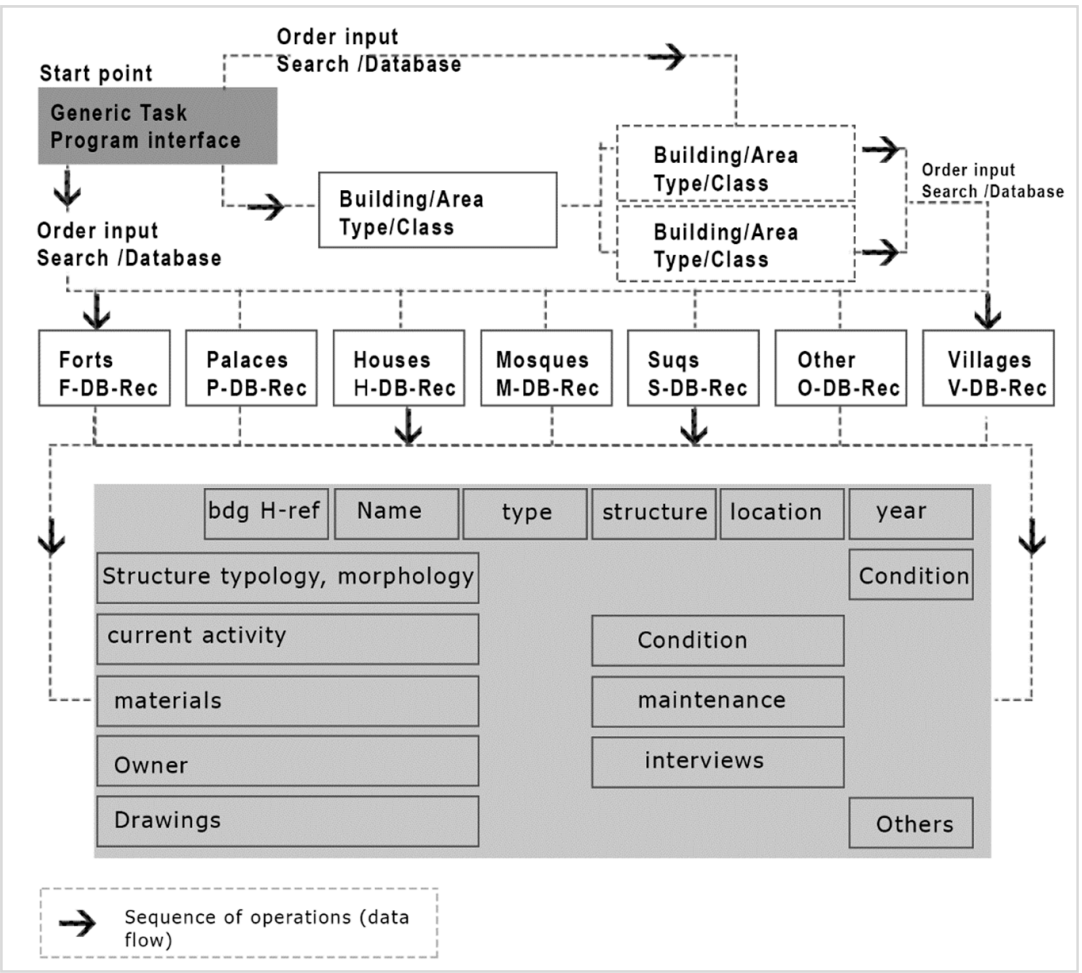

Figure 8. Qatar Historic Buildings Information Modeling (Q-HBIM) platform-database design and development: a schematic "organigram". 
By using Microsoft Excel sheets to formulate the initial database of the interactive platform, the survey of the buildings and sites has been divided according to use into (1) military buildings, (2) palaces, (3) domestic houses, (4) mosques, (5) souq, (6) villages and (7) other public buildings. Meanwhile, the survey tables classify the buildings according to name, location, year of construction, current situation, area, morphology, construction materials, current activity, and the type of ownership. Once the data has been transferred using an export plugin, it will automatically constitute the simple illustration of the platform basis for the FileMaker Pro.17 version (FileMaker Inc. subsidiary of Apple Inc., Santa Clara, CA. USA) database files. The analysis develops by initiating data collection and analysis matrix as shown in Figure 9 below. The list provides data-source files that are required to establish the database in itself in such a way that it allows a user-friendly interface.

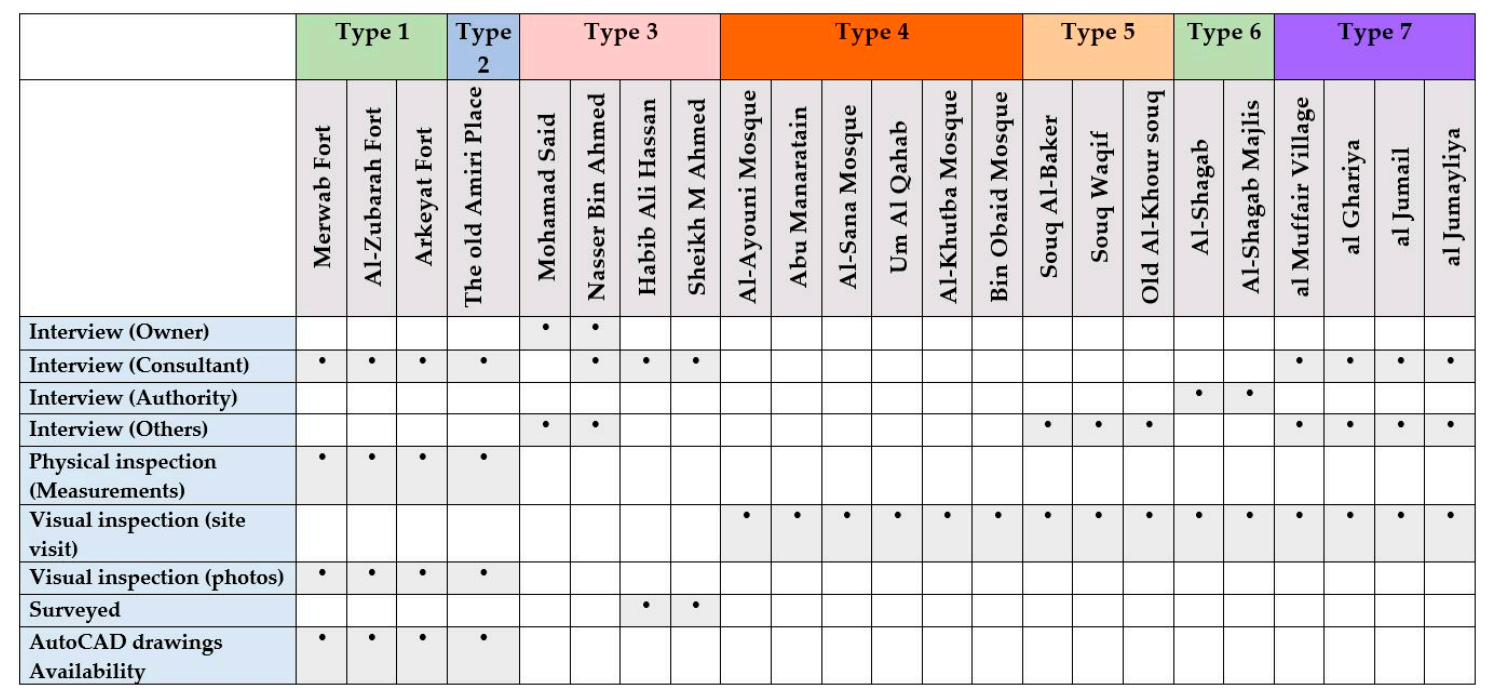

Figure 9. Data collection matrix.

The Q-HBIM platform is established in a configurative graphic display that summarizes the data collected from various sources. Table 4 shows the formation context, use, and ownership type related semantic for both types of military buildings and palaces. In fact, it allows the (near) real-time assessment of the studied building. Furthermore, it helps evaluate its physical condition for any urgent remedy action. Such cases refer to fortresses and palaces, as well as its potential application to domestic/houses in some exceptional scenarios. 
Table 4. Data analysis results (type: military buildings and palaces).

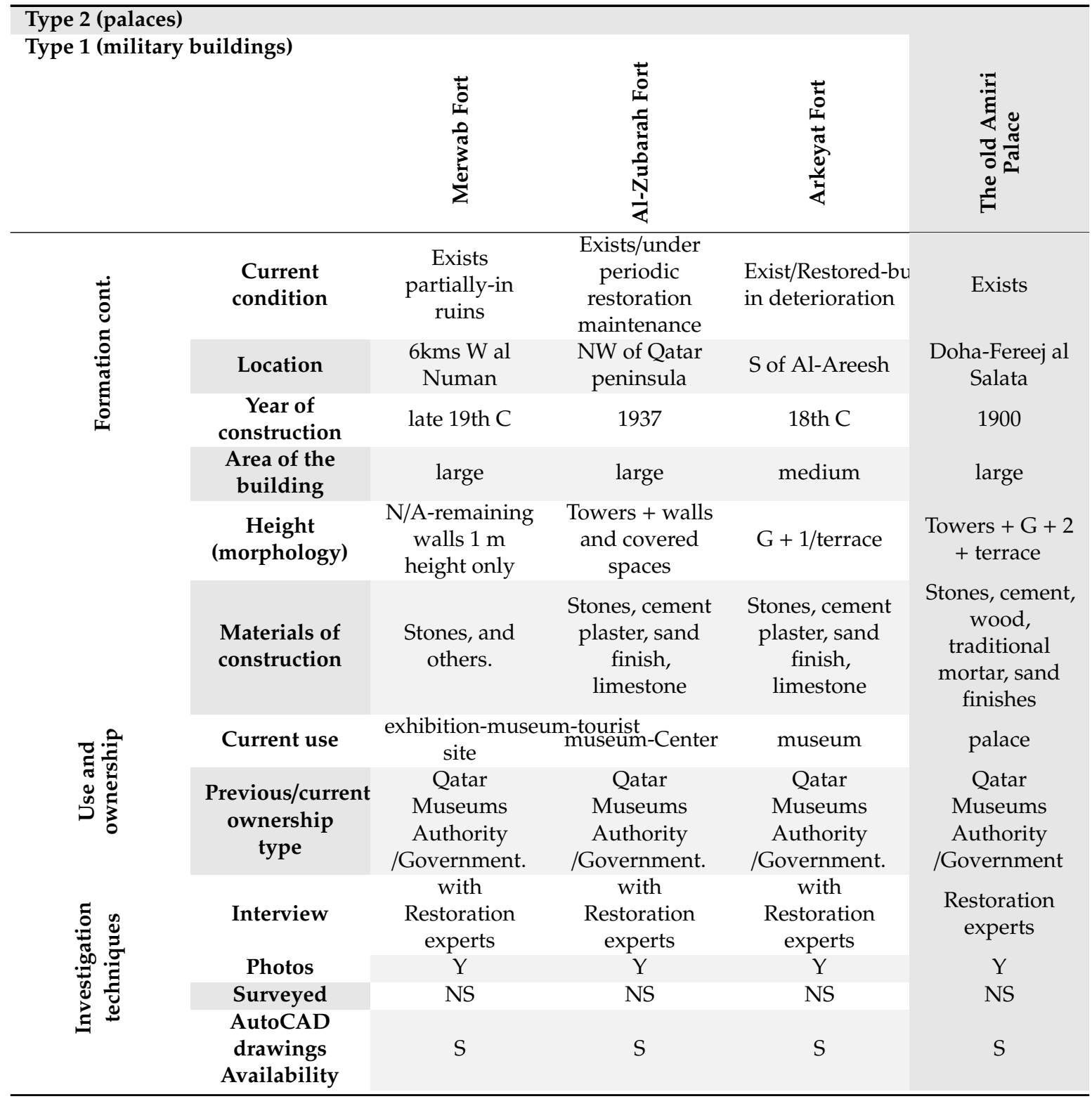

In the contrary, Tables 5 and 6 show the analysis of the gathered data for the types of domestic houses and mosques (religious structures). The investigated locations clearly present a serious level of deterioration where most of the buildings have either disappeared or are abandoned. Another aspect is shown through Tables 7 and 8, where the analysis and findings related to other public buildings such as suqs and villages identifies major danger from the neglect and demolition caused by physical deterioration of the buildings physical structures and surrounding sites. 
Table 5. Data analysis of domestic buildings (houses).

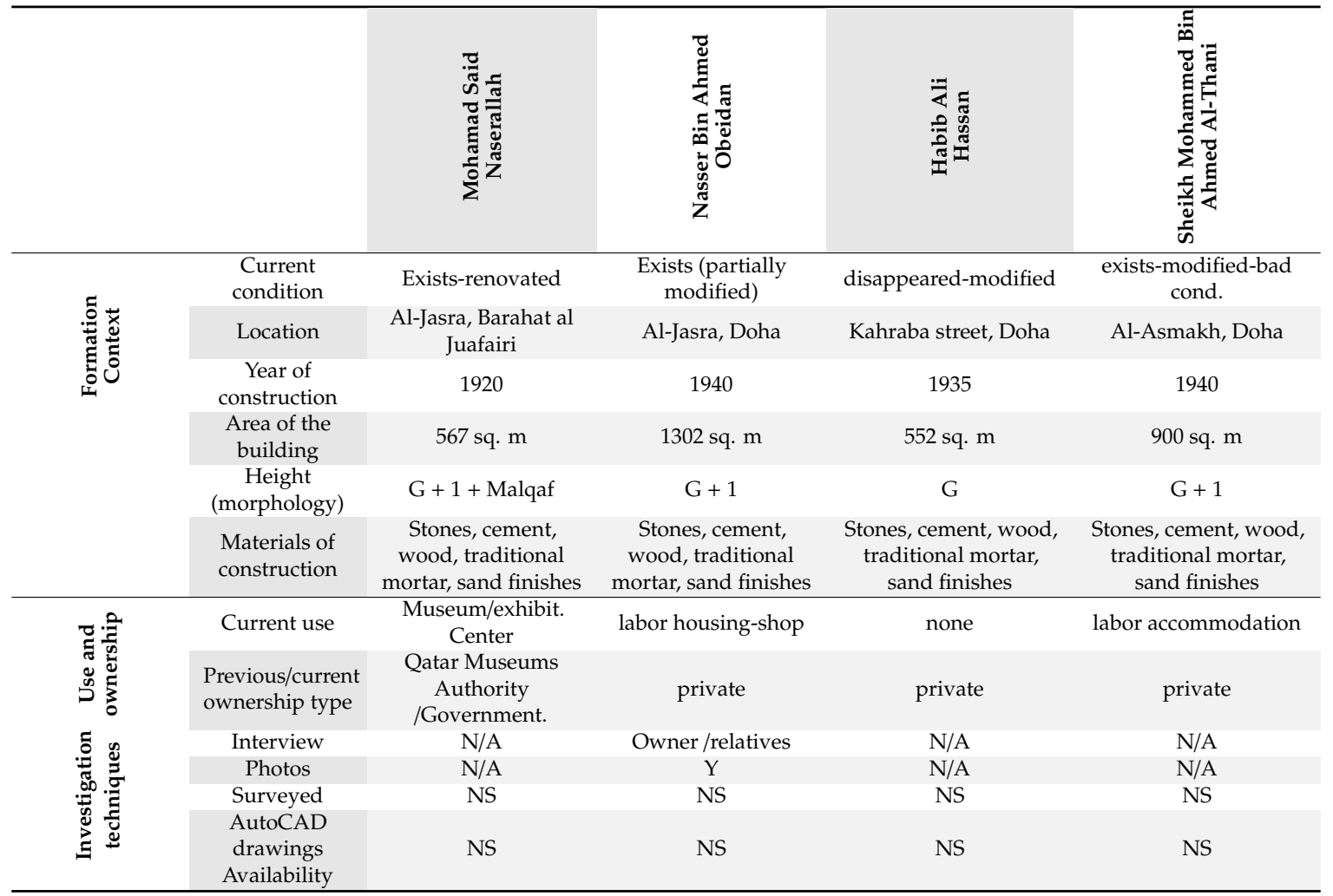

Table 6. Data analysis of religious buildings (Mosques).

\begin{tabular}{|c|c|c|c|c|c|c|}
\hline & & 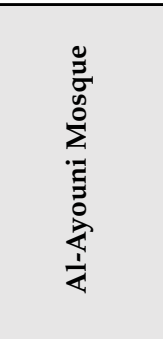 & 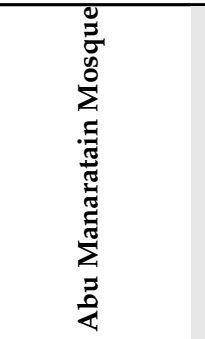 & 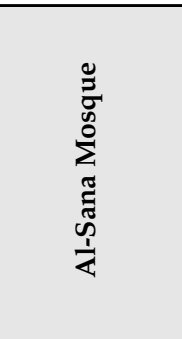 & 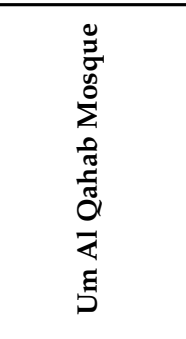 & 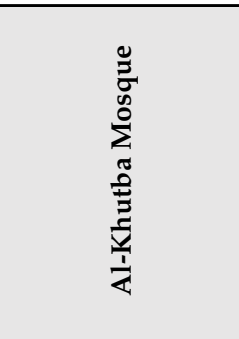 \\
\hline \multirow{7}{*}{ 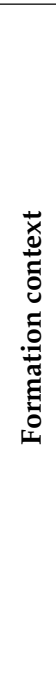 } & $\begin{array}{l}\text { Current } \\
\text { condition }\end{array}$ & abandoned & exists/Restored & abandoned & Exists & abandoned \\
\hline & Location & $\begin{array}{l}\text { south of } \\
\text { Doha - Al } \\
\text { Wakrah }\end{array}$ & Al Wakrah & $\begin{array}{l}\text { Al Sana } \\
\text { Village }\end{array}$ & $\begin{array}{l}\text { Um Al } \\
\text { Qahab } \\
\text { village }\end{array}$ & Dukhan \\
\hline & $\begin{array}{c}\text { Year of } \\
\text { construction }\end{array}$ & 1935 & 1940 & 1950 & 1945 & 1943 \\
\hline & $\begin{array}{l}\text { Area of the } \\
\text { building }\end{array}$ & $\begin{array}{c}17 \times 16 \\
\text { sq.mlargest } \\
\text { in Wakra }\end{array}$ & $27 \times 8$ sq.m & $10 \times 16$ sq.m & $\begin{array}{c}10 \times 14.25 \\
\text { sq.m }\end{array}$ & $10 \times 15$ sq.m \\
\hline & $\begin{array}{c}\text { Height } \\
\text { (morphology) }\end{array}$ & $\begin{array}{c}\mathrm{G}+ \\
\text { 1/Minaret } \\
(2.4 \mathrm{~m})\end{array}$ & $\begin{array}{c}\mathrm{G}+ \\
\text { 1/Minaret } \\
(9 \mathrm{~m})\end{array}$ & $\begin{array}{c}\mathrm{G}+ \\
\text { 1/Minaret } \\
(1.5 \mathrm{~m})\end{array}$ & $\begin{array}{c}\mathrm{G}+ \\
\text { 1/Minaret } \\
2.4 \mathrm{~m}\end{array}$ & $\begin{array}{c}\mathrm{G}+1 / \text { Minaret } \\
(2.25 \mathrm{~m})\end{array}$ \\
\hline & $\begin{array}{l}\text { Materials of } \\
\text { construction }\end{array}$ & $\begin{array}{c}\text { Stones, } \\
\text { traditional } \\
\text { cement, } \\
\text { limestone }\end{array}$ & $\begin{array}{c}\text { Stones, } \\
\text { traditional } \\
\text { cement, } \\
\text { wood, bricks, } \\
\text { limestone... }\end{array}$ & $\begin{array}{l}\text { Stones, } \\
\text { traditional } \\
\text { cement, } \\
\text { wood, bricks, } \\
\text { limestone } \\
\text { and plaster }\end{array}$ & $\begin{array}{l}\text { Stones, } \\
\text { traditional } \\
\text { cement, } \\
\text { wood, bricks, } \\
\text { limestone } \\
\text { and plaster }\end{array}$ & $\begin{array}{l}\text { Stones, traditional } \\
\text { cement, limestone }\end{array}$ \\
\hline & & & & $\ldots$ & $\ldots$ & \\
\hline
\end{tabular}


Table 6. Cont.

\begin{tabular}{|c|c|c|c|c|c|c|}
\hline & & 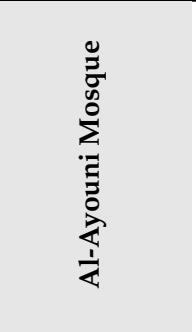 & 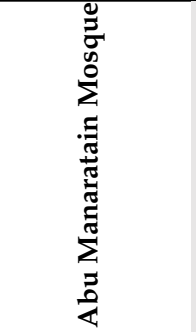 & 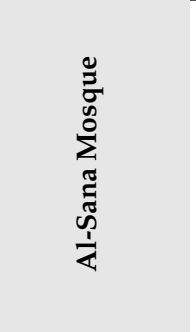 & 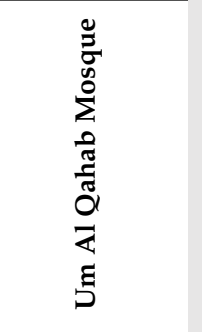 & 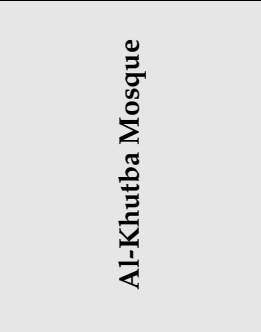 \\
\hline \multirow{6}{*}{ 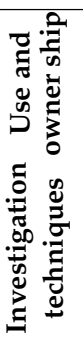 } & Current use & Mosque & Mosque & Mosque & Mosque & Mosque \\
\hline & $\begin{array}{l}\text { Previous/curre } \\
\text { ownership } \\
\text { type }\end{array}$ & Awqaf/private & Awqaf/Govern & Awqaf/Govern & Awqaf/Govern & Awqaf/Government \\
\hline & Interview & N/A & N/A & N/A & N/A & $\mathrm{N} / \mathrm{A}$ \\
\hline & Photos & N/A & N/A & N/A & N/A & N/A \\
\hline & Surveyed & NS & NS & NS & NS & NS \\
\hline & $\begin{array}{c}\text { AutoCAD } \\
\text { drawings } \\
\text { Availability }\end{array}$ & NS & NS & NS & NS & NS \\
\hline
\end{tabular}

Table 7. Data analysis: suqs.

\begin{tabular}{|c|c|c|c|c|}
\hline & & 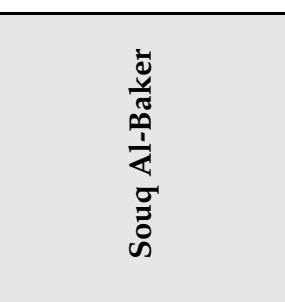 & 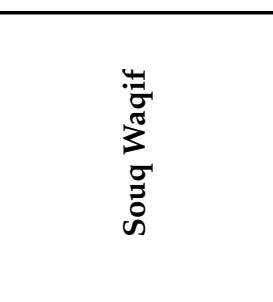 & $\begin{array}{l}\bar{\sigma} \\
\overline{0} \\
0 \\
\vdots \\
0 \\
\frac{1}{1} \\
\frac{1}{1} \\
\frac{\pi}{0} \\
\frac{0}{0}\end{array}$ \\
\hline \multirow{6}{*}{ 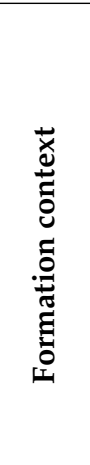 } & Current condition & demolished/reconst & $\begin{array}{c}\text { In use/ } \\
\text { Restored-reconst. }\end{array}$ & dilapidated/replaced \\
\hline & Location & Doha & Doha & al Khor \\
\hline & $\begin{array}{c}\text { Year of } \\
\text { construction }\end{array}$ & 1950 & 19th C & 1910 \\
\hline & $\begin{array}{l}\text { Area of the } \\
\text { building }\end{array}$ & $6 \times 30$ sq.m aprox & N/A & $27 \times 5 \mathrm{sq} / \mathrm{m}$ \\
\hline & $\begin{array}{c}\text { Height } \\
\text { (morphology) }\end{array}$ & $G+1 /$ Terrace & $\mathrm{G}+1-2-3 /$ Terrace & G/Terrace \\
\hline & $\begin{array}{l}\text { Materials of } \\
\text { construction }\end{array}$ & $\begin{array}{l}\text { Stones, traditional } \\
\text { cement, wood, } \\
\text { bricks, limestone }\end{array}$ & $\begin{array}{l}\text { Stones, traditional } \\
\text { cement, wood, } \\
\text { bricks, limestone }\end{array}$ & $\begin{array}{l}\text { Stones, traditional } \\
\text { cement, wood, } \\
\text { bricks, limestone }\end{array}$ \\
\hline \multirow{6}{*}{ 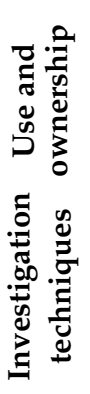 } & Current use & land reused & $\begin{array}{c}\text { Suq/Shops/Hotels } \\
\ldots\end{array}$ & $\begin{array}{l}\text { re-built/other } \\
\text { function }\end{array}$ \\
\hline & $\begin{array}{l}\text { Previous/current } \\
\text { ownership type }\end{array}$ & $\mathrm{N} / \mathrm{A}$ & $\mathrm{N} / \mathrm{A}$ & $\mathrm{N} / \mathrm{A}$ \\
\hline & Interview & N/A & N/A & N/A \\
\hline & Photos & N/A & N/A & N/A \\
\hline & Surveyed & $\mathrm{Y}$ & $\mathrm{Y}$ & $\mathrm{Y}$ \\
\hline & $\begin{array}{l}\text { AutoCAD } \\
\text { drawings } \\
\text { Availability }\end{array}$ & $\mathrm{Y}$ & $\mathrm{Y}$ & $\mathrm{Y}$ \\
\hline
\end{tabular}


Table 8. Data analysis: villages and other public buildings.

\begin{tabular}{|c|c|c|c|c|c|c|}
\hline & & 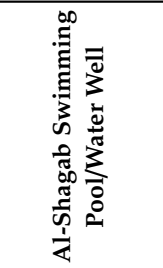 & 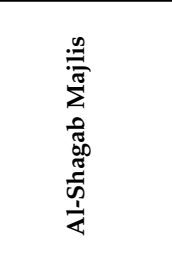 & 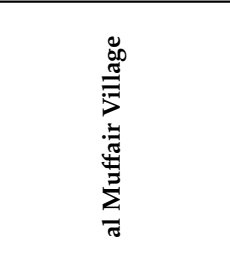 & 胥 & 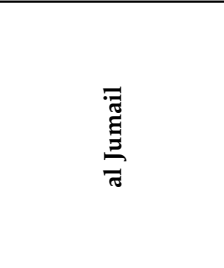 \\
\hline \multirow{6}{*}{ 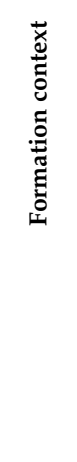 } & $\begin{array}{l}\text { Current } \\
\text { condition }\end{array}$ & Modified & exists-restored & exists-restored & under restoration & under restoration \\
\hline & Location & $\begin{array}{l}\text { al Rayyan, } \\
\text { Doha }\end{array}$ & $\begin{array}{l}\text { al Rayyan, } \\
\text { Doha }\end{array}$ & North & NW & NW \\
\hline & $\begin{array}{c}\text { Year of } \\
\text { construction }\end{array}$ & 1935 & $1930 \mathrm{~s}$ & N/A & N/A & N/A \\
\hline & $\begin{array}{l}\text { Area of the } \\
\text { building }\end{array}$ & $8 \times 6$ sq.m & $15 \times 8$ sq.m & Large land area & small land area & small land area \\
\hline & $\begin{array}{c}\text { Height } \\
\text { (morphology) }\end{array}$ & G & G & $G+1$ & $G+1$ & G \\
\hline & $\begin{array}{l}\text { Materials of } \\
\text { construction }\end{array}$ & $\begin{array}{c}\text { Stones, } \\
\text { traditional } \\
\text { cement, } \\
\text { wood, bricks, } \\
\text { limestone... }\end{array}$ & $\begin{array}{c}\text { Stones, } \\
\text { traditional } \\
\text { cement, } \\
\text { wood, bricks, } \\
\text { limestone... }\end{array}$ & divers & divers & divers \\
\hline \multirow{2}{*}{ 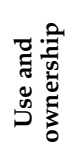 } & Current use & none & $\begin{array}{l}\text { other-exhibit } \\
\text { center }\end{array}$ & houses/shop/divers & houses/shop/divers & houses/shop/divers \\
\hline & $\begin{array}{l}\text { Previous/curre } \\
\text { ownership } \\
\text { type }\end{array}$ & N/A & N/A & Government & Government & Government \\
\hline \multirow{4}{*}{ 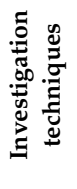 } & Interview & N/A & N/A & N/A & N/A & N/A \\
\hline & Photos & N/A & N/A & N/A & N/A & N/A \\
\hline & Surveyed & $\mathrm{Y}$ & $\mathrm{Y}$ & $\mathrm{Y}$ & $\mathrm{Y}$ & $\mathrm{Y}$ \\
\hline & $\begin{array}{l}\text { AutoCAD } \\
\text { drawings } \\
\text { Availability }\end{array}$ & $\mathrm{Y}$ & Y & Y & $\mathrm{Y}$ & Y \\
\hline
\end{tabular}

Once data acquisition is fully completed, post-processed analyzed data is exported and translated into FileMaker (FM) enabled databases. This integrates the shapes, forms and processes of operation and related maintenance as shown in the following Figures 10 and 11. Furthermore, another step links the semantics developed through the FM databases to the 3D model enabling a systemic develop of BIM model of related studied buildings and structures.

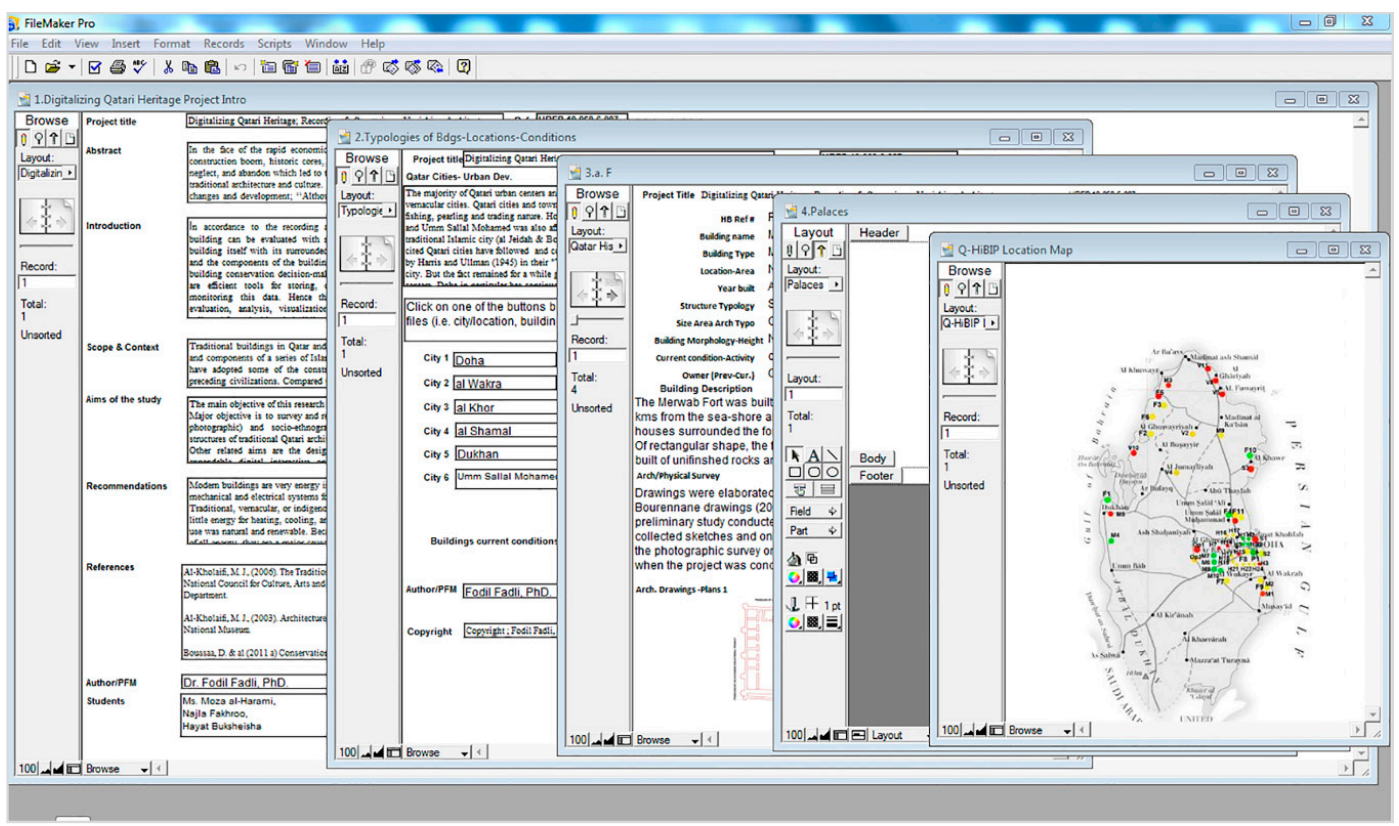

Figure 10. Q-HBIM Platform design and development (designed and developed by F. Fadli (C) 2012). 


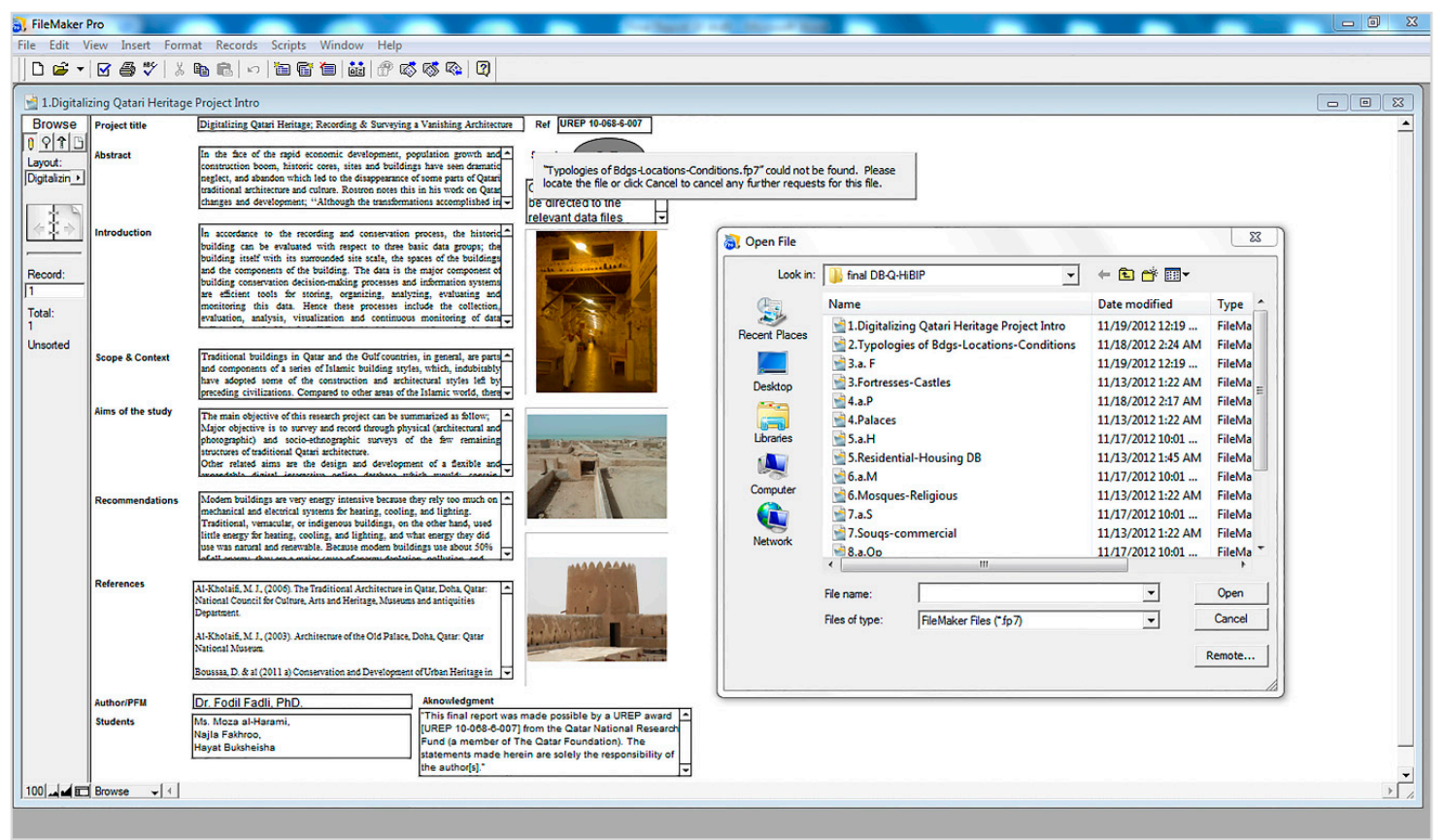

Figure 11. Q-HBIM Platform design and development (designed and developed by F. Fadli @ 2012).

\subsection{Data Evaluation and Interpretation}

According to the map in Figure 12; the majority of historic buildings are concentrated in the vicinity of Doha and, to a lesser extent, al-Wakrah in the South. This is mainly because of the capital-city status of Doha, and to the urban evolution of the country in general and Doha the capital city in particular.

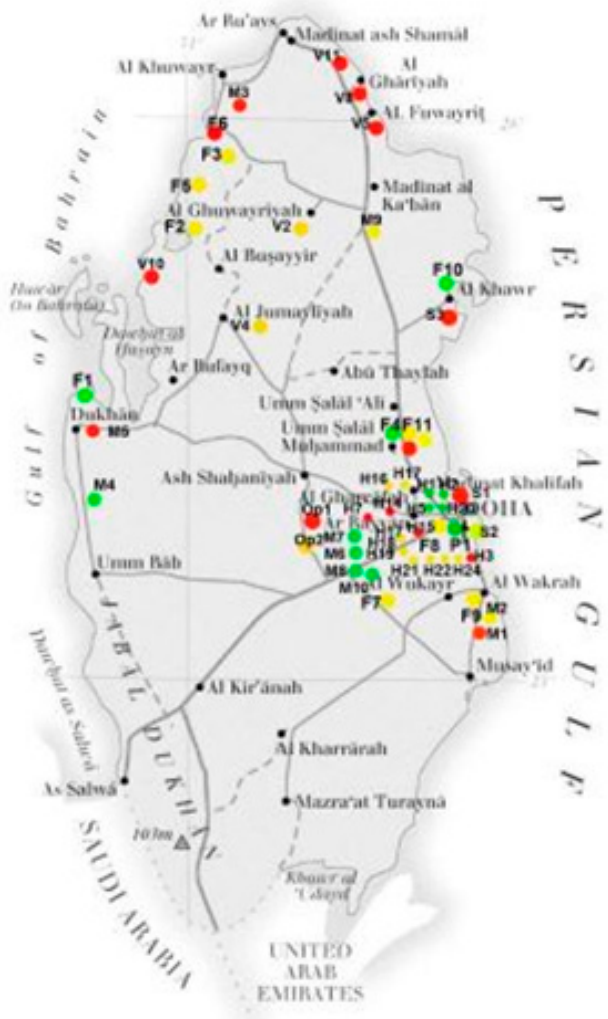

Figure 12. Location of historic building-interactive map used in the database platform for Q-HBIM (designed and developed by F. Fadli @ 2012). 
However, after data processing analysis, structures-related outcomes show that:

Military buildings (11 structures): Seven buildings still exist in total, meanwhile two buildings disappeared due to the lack of maintenance and restoration, and three buildings are partially existing with ongoing maintenance/restoration.

Palaces: one building investigated. It is kept in good physical and working conditions.

Domestic houses: 32 structures were investigated. Thirteen still exist and are in good operating conditions, whereas seven buildings only partially exist. Unfortunately, 12 structures have either been demolished or completely modified by the owners. This led to the loss of the building original character and therefore vanished heritage values.

Mosques: 34 structures were investigated in this research. Only 15 still exist and have been restored in the last decade. Thirteen structures were abandoned, and 6 have been or are under renovation and restoration.

Suqs: Three locations have been listed for the investigation, where only two suqs still exist meanwhile the other two have been removed or fully replaced with adaptive reuses. One demolished and one existing are located in the same location.

Other public buildings: Five buildings have been reviewed and investigated. Three buildings were restored and in operation. One building has been completely modified and another one is under restoration.

Villages: the investigation of villages included twelve locations. Eight villages have fully disappeared and three other locations have witnessed extensive reconstruction/restoration, of which only one site still exists and restoration has been completed recently (2017).

\section{Results and Discussion}

The stages of building restoration and area conservation processes in Qatar, as defined by the concerned cultural heritage conservation authorities, can be summarized as follows:

- The first step is to check if the building is worth restoring by testing its constructability.

- The second step is to examine and assess if the body of the building is reinforced and secured structurally.

- The third step is to define the changes needed for the restoration work, at all levels: structure, spatial, function, and aesthetics.

- The fourth step is to elaborate an adaptive re-use scenario plan as part of the restoration process.

It is worth mentioning that the dramatic dilapidation of historic vernacular buildings and structures in Qatar urges experts in all related fields to undertake emergency action plans in order to safeguard, protect and preserve the few remaining structures. A building, which dates back to the pre-1960s era, is considered as a built cultural heritage with related historic values in this research project. Table 9 below summarizes clearly the number of the historic buildings studied by different academics, architects and experts, and shows that their number has dramatically dropped. The mosques represent more than $50 \%$ of the remaining historic buildings in Qatar.

Table 9. Major studies and work related to the historic and heritage buildings in Qatar, with authors' extensive conditions survey of historic buildings (Fadli, 2012).

\begin{tabular}{|c|c|c|c|c|c|c|}
\hline $\begin{array}{l}\text { Study Author/ } \\
\text { Building Type }\end{array}$ & $\begin{array}{c}\text { French Archaeological } \\
\text { Mission }\end{array}$ & Al Khulaifi 2000 & GHD 2004 & $\begin{array}{c}\text { Jeidah \& } \\
\text { Bourenane } 2009\end{array}$ & $\begin{array}{c}\text { Boussaa et al. } \\
2010\end{array}$ & $\begin{array}{c}\text { Author All str. } \\
2012\end{array}$ \\
\hline Residential & $60^{+}$ & 6 & 29 & 24 & 23 & 23 \\
\hline Military & $10-12$ & $11^{1}$ & 6 & 5 & 3 & 6 \\
\hline Souqs & Approx. 6 & 1 & 2 & 2 & 3 & 3 \\
\hline Palaces & Approx. 3 & 1 & - & 1 & 1 & - \\
\hline Mosques & 70 & $29^{2}$ & 37 & 19 & 8 & 37 \\
\hline Other & 6 & 1 (Sikat) & $(3+12)^{3}$ & 4 & 2 & 1 \\
\hline Total studied & 100 circa. & 25 & 80 circa. & 55 & 43 & - \\
\hline Total listed & $157^{(+)}$ & 49 & $92^{+}$ & 55 & - & 72 \\
\hline
\end{tabular}


Restoration and conservation experts mention that a building lives by its use [2,27]. Survival of historic buildings is often dependent on robustness of use as well as the durability of structure [7]. Hence, it is obvious that the mosques represent the major part of historic buildings which still survive until today, as their use is sustained, and their maintenance is efficient and costs less [29]. Houses and residential buildings have been preserved to a certain extent. However, they have faced either partial demolition, modification or total reconstruction. Their use has been kept to its original function, or minor additional activities were added. Forts, fortresses and towers represent the military buildings. These categories represent the oldest historic buildings in Qatar. Despite their function as tourist attraction, these structures have faced advanced decay. A few of them have been safeguarded due to the efforts of the Emiri Diwan, the government and Ministry of Culture and QMA.

Nowadays, Qatari traditional architecture is facing the dilemma of total dilapidation or a restoration involving a multitude of issues. The most alarming is the use of inadequate materials or inappropriate techniques of restoration, conservation and rehabilitation. The use of modern materials such as concrete and cavity bricks, does not fit with the traditional local materials such as adobe mud, wood and stone used in vernacular buildings (Figures 13 and 14).

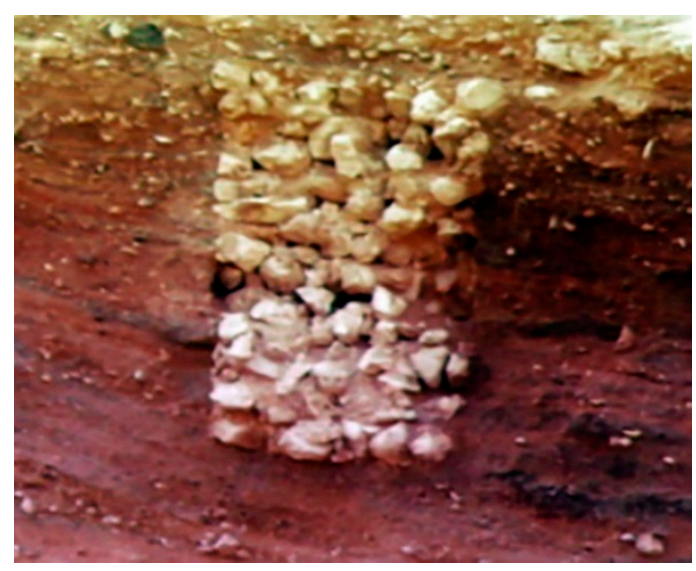

Figure 13. The use of local materials in traditional vernacular buildings (remains found under the pavements of the re-constructed Suq Waqif).

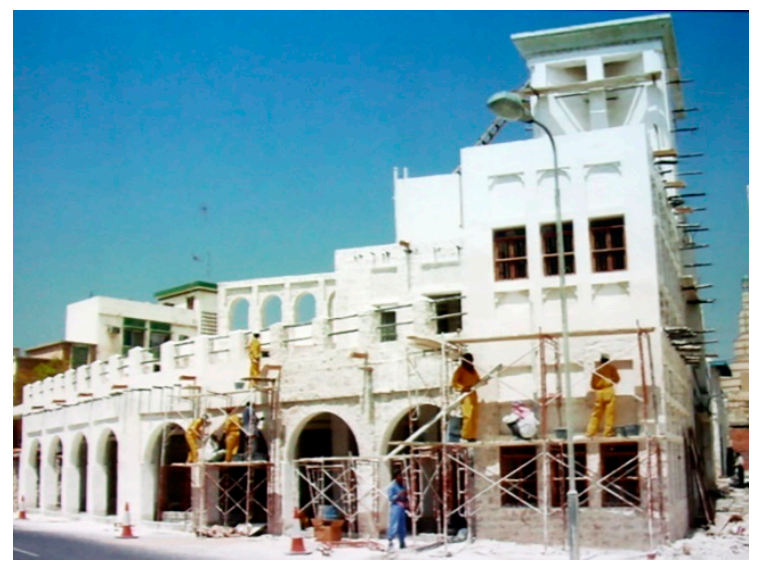

Figure 14. The use of non-local, non-traditional materials on existing traditional vernacular buildings (restoration or reconstruction: a dilemma).

\section{Conclusions}

Survival of historic buildings often depends on robustness of use as well as durability of structure [7]. However, uses rooted in vernacular traditions and social well-being are destroyed by the conveniences and practicalities of modern life. 
Preserving cultural built heritage through digitized recording and archiving is vital for vernacular architecture and its survival. Today, technologies and applications form advanced instruments that facilitate and enhance the cultural heritage preservation process. Protecting and preserving vanishing built heritage is important to not only protect and safeguard the tangible physical dimension of it, but also its intangible impact on of cultural values and the social practice of its inhabitants. The present study provides a useful set of recommendations to digitize, record and promote cultural heritage preservation using 21st Century technologies as per the following main aspects:

1. A Preservation Policy

A well-defined and timely updated preservation strategy and a related local conservation charter must be formulated. This will set a clear practical framework enabling a BIM ontology for heritage buildings in Qatar. It will reflect the meaning of heritage and its impact on its context.

2. Preservation Processes

The State of Qatar has one of the fastest growing economies in the world. This has led to a rapid transformation of its cities which resulted in the loss of large facets of its built cultural heritage over the last decades. Therefore a dedicated heritage preservation authority must be established with the aim of transferring the semantics of buildings and cities into a structured digital database as the proposed Q-HBIM. The role of the authority must include all related fields such as archaeology, history, architecture, civil engineering and information management. Furthermore, the processes of preservation and restoration must be clear and follow a strict framework that includes;

- Theoretical study of the built herniate (the authenticity of locations).

- Empirical study to list and categorize the locations components and its value to culture.

- Physical survey and data collections.

- Data categorization and heritage modelling.

- Continuous monitoring and data management.

\section{Preservation Tools}

The present study confirmed that conventional methods of heritage documentation are not efficient anymore. It is known that digitized recording of the cultural built heritage requires a large amount of resources, time and effort. Hence, the process itself is complex and includes a series of operations and actions. From the physical surveying and data-capture to data registration, pre-processing and full processing to drafting, modelling and real-time monitoring; to finally the post- construction results. These heterogeneous datasets are complex and hard to structure and manage. Technology components such as computational systems, 3D modelling and simulation programs, advanced scanning and archiving technologies and information management systems obtain high capacity to facilitate the digitization process. The overall guidelines of digitizing the heritage (built and non-built) have to adopt the principles of data acquisition, semantics, and 3D modelling simultaneously in order to achieve an efficient HBIM model.

Therefore, the role of Qatar Historic Buildings Information Modelling (Q-HBIM) platform, extends beyond the archival aim. It aims to reach the requirement of an interactive and open access source of historical information that lists and categorizes the large amount of data in a flexible expandable database using 21st Century cutting-edge technologies. Further developments would include the use of Virtual Reality (VR) and Artificial Intelligence (AI) in the 4th Industrial Revolution era. This would be Q-HBIM 4.0.

Author Contributions: Individual contributions were as follows "conceptualization, F.F.; methodology, F.F.; software, F.F.; validation, F.F.; formal analysis, F.F.; investigation, F.F.; resources, F.F.; data curation, F.F.; writing-original draft preparation, F.F.; writing —-review and editing, F.F.; visualization, F.F.; and M.A.; supervision, F.F.; project administration, F.F.; funding acquisition, F.F.".

Funding: This publication was made possible by a UREP award [UREP 10-068-6-007] from the Qatar National Research Fund (a member of The Qatar Foundation). The statements made herein are solely the responsibility of the author[s]. 
Acknowledgments: The authors would like to thank Najeeba Kutty for her technical support, as well as ex-UG students researchers Moza AlHarami, Najla Fakhroo, and Hayat Buksheisha for their support while conducting related on-site buildings surveys. The publication of this article was funded by the Qatar National Library.

Conflicts of Interest: The authors declare no conflict of interest.

\section{References}

1. Rostron, M. Liberal arts education in Qatar: Intercultural perspectives. Intercult. Educ. 2009, 20, $219-229$. [CrossRef]

2. Fadli, F. Digitizing vanishing heritage in the MENA region: Case of Qatar. In Proceedings of the Qatar Foundation Annual Research Conference, Doha, Qatar, 24-25 November 2013.

3. Yilmaz, H.; Yakar, M.; Yildiz, F. Documentation of historical caravansaries by digital close range photogrammetry. Autom. Constr. 2008, 17, 489-498. [CrossRef]

4. Berndt, E.; Carlos, J. Cultural heritage in the mature era of computer graphics. IEEE Comput. Graph. Appl. 2000, 20, 36-37. [CrossRef]

5. Fischer, A.; Manor, A.; Barhak, Y. Adaptive parameterization for reconstruction of 3D freeform objects from laser-scanned data. In Proceedings of the Computer Graphics and Applications, Seventh Pacific Conference IEEE, Seoul, Korea, 5-7 October 1999.

6. Roberts, P. The evolution, definition and purpose of urban regeneration. In Urban Regeneration; SAGE Publications Inc.: New York, NY, USA, 2000; pp. 9-36.

7. Fadli, F.; Sibley, M. The Historic hammāms of Cairo: Safeguarding a vanishing heritage. J. Archit. Conserv. 2008, 14, 59-80. [CrossRef]

8. Davoudi, S.; Graham, S.; Madani-Pour, A. Managing Cities: The New Urban Context; Praeger: Westposrt, CT, USA, 1995.

9. Montgomery, J. Urban vitality and the culture of cities. Plann. Pract. Res. 1995, 10, 101-109. [CrossRef]

10. Binay, R.A. Urban Regeneration Policy Impacts on the Future of City-A Comparative Study in European and The Turkish Context; İzmir Institute of Technology: İzmir, Turkey, 2007.

11. Bianchini, F. Culture, conflict and cities: Issues and prospects for the 1990s. In Cultural Policy and Urban Regeneration: The West European Experience; Manchester Unversity Press: Manchester, UK, 1993; pp. 199-213.

12. Ciftci, C.; Meshur, H.F.A.; Sehrat, M.Y.; Yavuz, F.; Levend, S. Urban Regeneration strategies in historical city center of Beysehir-Konya/Turkiye. In Proceedings of the 14th IPHS Conference, Istanbul, Turkey, 12-15 July 2010.

13. Jokilehto, J. Definition of cultural heritage, References to documents in history. In ICCROM Working Group Heritage and Society; ICCROM: Rome, Italy, 2005; pp. 4-8.

14. Stanco, F.; Battiato, S.; Gallo, G. Digital Imaging for Cultural Heritage Preservation: Analysis, Restoration, and Reconstruction of Ancient Artworks; CRC Press: Boca Raton, FL, USA, 2011.

15. De Reu, J.; Plets, G.; Verhoeven, G.; De Smedt, P.; Bats, M.; Cherrette, B.; De Maeyer, W.; Deconynck, J.; Herremans, D.; Laloo, P.; et al. Towards a three-dimensional cost-effective registration of the archaeological heritage. J. Archaeol. Sci. 2013, 40, 1108-1121. [CrossRef]

16. Rioux, M. Digital 3D imaging: Theory and Applications; Videometrics III; International Society for Optics and Photonics: Bellingham, WA, USA, 1994.

17. Salvi, J.; Pages, J.; Batlle, J. Pattern codification strategies in structured light systems. Pattern Recognit. 2004, 37, 827-849. [CrossRef]

18. Lensch, H.P.; Heidrich, W.; Seidel, H.-P. A silhouette-based algorithm for texture registration and stitching. Graph. Model. 2001, 63, 245-262. [CrossRef]

19. Bouguet, J.-Y.; Perona, P. 3D photography on your desk. In Proceedings of the Sixth International Conference on Computer Vision (IEEE Cat. No. 98CH36271), IEEE, Bombay, India, 7 January 1998.

20. Livieratos, E. Empiric, topographic or photogrammetric recording? Answers to properly phrased questions. In Proceedings of the Congress Terrestrial Photogrammetry and Geographic Information Systems for the documentation of the National Cultural Heritage, Ioannina, Greece, 30 November 1992.

21. Tsioukas, V.; Patias, P. Low cost 3D visualization and measuring 'tool' in the service of archaeological excavations. In Proceedings of the Computer Applications and Quantitative Methods in Archaeology Conference, The Digital Heritage of Archaeology, Heraklion, Greece, 25 April 2002. 
22. James, L.A.; Walsh, S.J.; Bishop, M.P. Geospatial Technologies and Geomorphological Mapping; Elsevier: Amsterdam, The Netherlands, 2012.

23. Hanke, K.; Grussenmeyer, P. Architectural Photogrammetry: Basic Theory, Procedures, Tools; ISPRS Commission; Taylor \& Francis: Abington, UK, 2002.

24. Fonstad, M.A.; Dietrich, T.J.; Courville, B.C.; Jensen, J.L.; Carbonneau, P.E. Topographic structure from motion: A new development in photogrammetric measurement. Earth Surf. Process. Landf. 2013, 38, 421-430. [CrossRef]

25. Borkowski, A.; Jozkov, G.; Ziaja, M.; Beck, K. Accuracy of 3D building models created using terrestrial and airborne laser scanning data. In Proceedings of the FIG Congress, Kuala Lumpur, Malaysia, 16-21 June 2014.

26. Daneshpour, M. Providing 3 dimensional models of historical buildings using laser scanners. In Proceedings of the 2009 Geomatics Congress, Tehran, Iran, 11-13 May 2009.

27. Fadli, F.; Barki, H.; Boguslawski, P.; Mahdjoubi, L. 3D scene capture: A comprehensive review of techniques and tools for efficient life cycle analysis (LCA) and emergency preparedness (EP) applications. In Building Information Modelling (BIM) in Design, Construction and Operations; WIT Press: Southampton, UK, 2015; pp. 85-96.

28. Fadli, F.; Barki, H.; Shaat, A.; Mandjoubi, L.; Boguslawski, P.; Zverovich, V. 3D capture techniques for BIM enabled LCM. In Proceedings of the IFIP International Conference on Product Lifecycle Management, Doha, Qatar, 19-21 October 2015.

29. Fadli, F.; Sobhey, R.; Asadi, R.; Elsarrg, E. Environmental impact assessment of new district developments. WIT Trans. Built Environ. 2014, 142, 517-528.

(C) 2019 by the authors. Licensee MDPI, Basel, Switzerland. This article is an open access article distributed under the terms and conditions of the Creative Commons Attribution (CC BY) license (http://creativecommons.org/licenses/by/4.0/). 